University of Zurich

Department of Economics

Working Paper Series

ISSN 1664-7041 (print)

ISSN 1664-705X (online)

Working Paper No. 340

\title{
The Macroeconomics of Automation: Data, Theory, and Policy Analysis
}

Nir Jaimovich, Itay Saporta-Eksten, Henry Siu and Yaniv Yedid-Levi

January 2020 


\title{
The Macroeconomics of Automation: Data, Theory, and Policy Analysis*
}

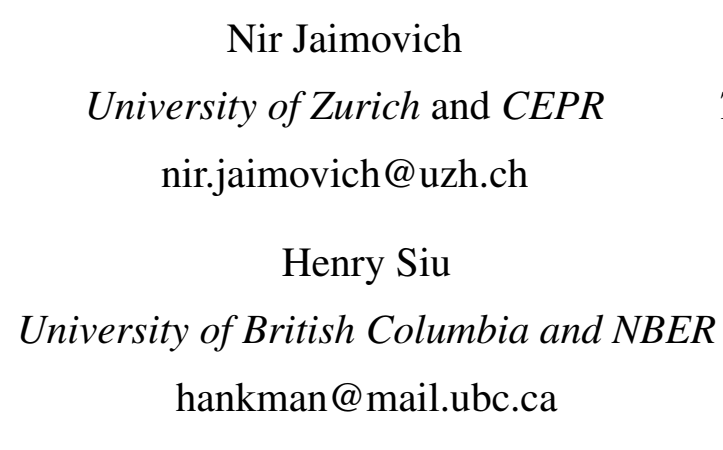

January 2020

\begin{abstract}
The U.S. economy has experienced a significant drop in the fraction of the population employed in middle wage, "routine task-intensive" occupations. Applying machine learning techniques, we identify characteristics of those who used to be employed in such occupations and show they are now less likely to work in routine occupations. Instead, they are either non-participants in the labor force or working at occupations that tend to occupy the bottom of the wage distribution. We then develop a quantitative, heterogeneous agent, general equilibrium model of labor force participation, occupational choice, and capital investment. This allows us to quantify the role of advancement in automation technology in accounting for these labor market changes. We then use this framework as a laboratory to evaluate various public policies aimed at addressing the disappearance of routine employment and its consequent impacts on inequality.

Keywords: Polarization, Automation, Routine Employment, Labor Force Participation, Universal Basic Income, Unemployment Insurance, Retraining.
\end{abstract}

${ }^{*}$ We thank Adrien Aucert, Zsofia Barany, Gadi Barlevy, Larry Christiano, Max Dvorkin, Ester Faia, Yuriy Gorodnichenko, Zvi Hercowitz, Chad Jones, Joseba Martinez, Gabriel Mathy, Pete Klenow, Gianluca Violante, and numerous seminar audiences for helpful comments. All errors are our own. 


\section{Introduction}

Advances in automation technologies have left an indelible mark on the labor market of the U.S. and other industrialized economies over the past 40 years. An important literature demonstrates that these economies have experienced a significant drop in the fraction of the population employed in jobs in the middle of the occupational wage distribution (see, for instance, Autor, Katz and Kearney (2006), Goos and Manning (2007), Goos, Manning and Salomons (2009), Acemoglu and Autor (2011)). This hollowing out of the middle is linked to the decline of employment in routine occupations - those that focus on a limited set of tasks that can be performed by following a well-defined set of instructions and procedures. The routine nature of these tasks make them prime candidates to be performed by automation technologies (see Autor, Levy and Murnane (2003), and the subsequent literature).

This paper contributes to our understanding of this phenomenon along three dimensions. First, we apply machine learning techniques that allow us identify who are the workers with "routine occupational characteristics." With this chracterization in hand we track the labor market outcomes of the this type of individuals. Our key empirical findings is that the likelihood of this type of individuals to work in routine occupations has fallen significantly. Instead, they are now either non-participants in the labor force or working at occupations that tend to occupy the bottom of the wage distribution.

What is causing this change in the likelihood to work in routine, middle-class, occupations? While there is ample research identifying technological change and automation as the primary factor, there could naturally be other complementary forces (see Section 2 for a discussion). Our second contribution is to quantify the specific role of automation. To do so, we develop in the second part of the paper a quantitive heterogeneous agent general equilibrium model of labor force participation, occupational choice, unemployment, and investment dynamics. We find that automation accounts for about half of the fall in the likelihood of working in routine occupations that we document for routine type individuals. Moreover, we use the model to study the aggregate and distributional effects of automation both in terms of allocations and welfare.

Given that we find an important quantitative role for automation, our third contribution is to use our new framework as a "laboratory" to evaluate various public policy proposals, where, given the general equilibrium emphasis of the model, each of the policies we consider must be financed through increased government distortionary taxation.

In what follows, we discuss each of these three parts in detail. In Section 2, we use data from the Current Population Survey (CPS) during the "pre-polarization" period of 1984-1989, to train a random forest algorithm to classify individuals in an agnostic manner. The algorithm classifies individuals into different 
categories based on their "occupational likelihoods" allowing us to identify routine occupational characteristics. With this mapping we then track the evolution of individuals with such characteristics over time, and ask what has happened to the type of workers who would otherwise be employed in routine occupations during the "post-polarization" era. Are "routine-type" workers employed in different occupations now than they used to be? Do they tend to participate less in the labor force than they used to? Are they more often unemployed than they used to be?

Our key finding is that such routine-type individuals have experienced a fall of about $16 \%$ in the likelihood of working in routine occupations between the pre-polarization era and the post-polarization one. This decline in the likelihood of routine employment must be offset by an increase in the likelihood of being in other labor market statuses; we find that instead of working in routine occupations, about two-thirds of such individuals have ended up as non-participants in the labor force, with the remaining one-third employed in non-routine manual occupations (that tend to be at the bottom of the occupational wage distribution). Interestingly, we find that the unemployment rates for such workers remained roughly unchanged. We complement this analysis using the National Longitudinal Survey of the Youth (NLSY) 1979 and 1997. We show that similar patterns are observed for young low cognitive ability workers (as measured by AFQT scores), who used to work in routine occupations in the late 1980s.

These findings guide the setup and calibration of a general equilibrium model which we present in Section 3. We have three goals in mind. First, we use the model as a measurement device in order to quantify the specific role of automation in the fall in the likelihood of working in routine occupations for these individuals. Second, we use the model to assess the distributional effects of advanced automation. Third, we use the model to quantify the effects of various policy reforms. In what follows we briefly describe below the structure of the model and the main results.

Given our quantitative goal, we focus on a tangible measure of automation and its technological progressspecifically, information-and-communication-technology (ICT) capital that has been shown to capture various aggregate trends when embedded into a macroeconomic model (e.g., shares in overall investment and labor shares of national income; see Eden and Gaggl (2018)). Firms invest optimally in capital, so that the degree of ICT adoption/automation is endogenous.

Since occupational employment is central to our analysis and empirical findings, we consider a model with three occupations: (i) non-routine cognitive (NRC), (ii) routine (R), and (iii) NRM, that represent high, middle, and low paying jobs, respectively 1 In the model, individuals with routine occupational characteristics (i.e. those who cannot work as NRC) vary in terms of their work ability in R and NRM occupations.

\footnotetext{
${ }^{1}$ See for instance, Autor, Katz and Kearney (2006), Goos and Manning (2007), and Jaimovich and Siu (2012)).
} 
Based on their abilities and equilibrium wages, workers optimally decide whether or not to participate in the labor force and, conditional on participating, sort into occupations. Labor force participants are either employed or unemployed due to search-and-matching frictions (Diamond (1982), Mortensen (1982) and Pissarides (1985)). Given our interest in policy analysis, we introduce labor market frictions since certain interventions are targeted at the unemployed, while others affect the relative value of unemployment versus other labor market statuses. All government programs are financed with labor income and profit taxation.

Importantly, the substitutability between ICT capital and R occupational labor is disciplined by the data and any channel that affects firms optimal adoption of ICT capital affects the return to be working in a R vs. NRM occupation and the return to labor force participation.

We characterize the model equilibrium in Section 4 and discuss calibration and quantitative results in Section 5. We find that the price decline of ICT since 1989 can account for about $50 \%$ of the decline in R employment. Moreover, our model results indicate a the presence of significant heterogeneity in the welfare implications of automation; workers who used to work in R occupations see a significant decline in their wages, and thus in their welfare. On the other hand, due to complementarity with automation technology, and to the capital ownership structure in the economy, NRC workers see large increases in their welfare.

In Section 6, the model is used as a laboratory to evaluate the aggregate and distributional effects of various policies. We consider two sets of policies where each is funded by distortionary taxation. First, we study the effect of an "occupational retraining" policy that is aimed at counteracting the effects of automation. The program is aimed at labor force non-participants, improving their ability in NRM work. The policy induces workers back into the labor market, and improves their welfare. But this harms others: a displacement effect implies that newly trained workers compete with those who already selected, prior to the retraining program, into NRM work, pushing down their wages, employment, and welfare.

The second set of policies are explicitly redistributive, transferring resources from high-wage workers (who, as the model shows, significantly benefit from automation) to middle- and low-wage workers. In these experiments, the unemployment margin plays a critical role. We consider: (i) increasing unemployment insurance benefits, (ii) introducing a universal basic income, (iii) increasing transfers to labor force nonparticipants, and (iv) changes in the progressivity of the tax system. While (i) is modestly successful in improving average welfare of all groups, policies (ii) and (iii) impose large welfare losses to high-wage workers and are very costly in terms of aggregate income. In contrast, (iv) demonstrates that a (much) more progressive tax system, with a reduction in the taxes levied on low-earners and balancing the budget by increasing the taxes on high-earners, can achieve much of the redistribution gains, but without an output decline, and with much smaller welfare losses for high income earners. 
Finally, Section 7 concludes the paper, while the different Appendices discuss various robustness checks, both empirically and theoretically.

\section{Employment and Occupation Trends}

An important literature documents the changes in the task content of work, its relation to the decline in the cost of industrial robotics, computing, and information technology, and its implications for the structure of occupational employment and wages (see for example Autor, Levy and Murnane (2003), Acemoglu and Autor (2011), Autor and Dorn (2013) and Atalay et al. (2018)). Relatedly, there is an emerging literature that empirically asses the impact of automation on routine employment. For example, looking across countries, Michaels, Natraj and Van Reenen (2014) find that the greater the increase in ICT investment (at the industrycountry level) is, the greater the increase in the high-skilled labor share and the the decrease in the middleskill share of labor income is (with insignificant effects on the least-skilled group). Similarly, Acemoglu and Restrepo (2019) consider variation across US commuting zones and find negative labor market effects given industry specific robotic penetration. Finally, Gaggl and Wright (2017) and Tuzel and Zhang (2019) use tax reforms in the U.K (the former) and the U.S. (the latter) that increase the incentives of ICT investment; both papers find that the increase in ICT reduces the number of workers who perform R tasks while rewarding workers engaged in non-routine, cognitive-intensive task

In this section we add to this literature by pursuing the following goal. We aim to document what has happened to workers with "routine occupational characteristics" who would have been likely employed in $\mathrm{R}$ occupations in the 1980 s, a period we refer to as the "pre-polarization." Are they employed in other occupations? Are they unemployed more frequently? Are they more likely to be out of the labor force? Answering these questions is challenging as it involves a counterfactual experiment, where we must decide which of the workers observed in the "post-polarization" period of the data, are those who would be $\mathrm{R}$ workers if they were observed in the pre-polarization.

To do this, we consider an empirical framework that classifies individuals according to their likelihood of employment in various occupational groups based on their observed characteristics during the late 1980s. With this mapping between characteristics and specific occupations (e.g. R task-intensive ones), we then track the actual employment and occupational choices of individuals with "routine occupational characteristics" over time as automation advances.

Before proceeding, it is useful to compare this to alternative approaches using panel data following specific individuals ${ }^{2}$ One could follow the evolution of the distribution of labor force and occupational choices

\footnotetext{
${ }^{2}$ Two candidate datasets are the 1979 National Longitudinal Survey of Youth (NLSY) and the Panel Study if Income Dynamics
} 
of the 1980s cohort of routine workers. While this approach has natural appeal, it has two major disadvantages. First, such an exercise only follows a single cohort (or small number of cohorts) of individuals, and would be uninformative of the impact of automation on others cohorts, such as young workers entering the labor market at the turn of the 21st century. Second, the long-run labor market transitions of individuals over three decades confound macroeconomic effects with life-cycle effects-for example, the fact that individuals are more likely to get "promoted" to managerial occupations later in life, independent of advances in automation.

Our approach circumvents these issues. We do not attempt to track individuals who worked in a routine occupation over time. Instead, in each year we look for individuals with similar characteristics to those of routine workers in the late 1980s. By identifying these "likely routine" workers, we can analyze the labor market outcomes of the cross-section of such worker types over time, in a way that is not cohort-specific and does not confound life-cycle effects.

\subsection{Where do workers in declining occupations go? A machine learning approach}

We classify prime-aged individuals (25-64 years of age) from the CPS into types based on the occupation they would most likely have been employed in the pre-polarization era, before the rise of automation. To obtain such a classification, we apply a random forest, machine learning (hereafter ML) algorithm using age, education, gender, and race as observable characteristics in a flexible manner. Unlike previous work, such as Cortes, Jaimovich and Siu (2017), the ML approach uses this information in a flexible and agnostic manner, that does not require us to pre-specify which characteristics, e.g. which age groups are "likely routine."

The occupational classification draws distinctions based on task intensity along two dimensions. The first is whether an occupation is routine or non-routine. The second is based on whether it is "cognitive" versus "manual" in task intensity. We thus end up with four categories of occupations: non-routine-cognitive (NRC); routine-cognitive (RC); non-routine-manual (NRM); and routine-manual (RM). Our occupation classification follows Jaimovich and Siu (2012); for more details about variable and sample definitions see Appendix A.1.1.

We use cross-sectional data on employed individuals using their current occupation, and unemployed individuals using their most recent occupation of employment. We do this during the pre-polarization period (defined as 1984-1989) to train the ML algorithm to associate occupations to individual-level characteristics, where we pick 1989 as the benchmark year for comparisons, since per capita routine employment peaked (PSID); for example, Cortes (2016) uses the PSID to study short-run occupation switching dynamics through the lens of labor market automation. 
that year (see for example Cortes, Jaimovich and Siu (2017)). We then apply the algorithm to assign persons to occupations in the remaining CPS subsamples. First, we use the predictions to assign the most likely occupation to labor force non-participants during the pre-polarization period. Second, we roll the predictions forward in time, 1990-2017, and predict occupations for all individuals. Doing so allows us to predict participation and occupational choices for all individuals had there been no changes in the economy.

\subsection{Results}

While our ML approach classifies individuals into four occupational groups, we present results here aggregating to two occupational types: $N R C$ and non-NRC (i.e., RC, RM, and NRM). For the sake of exposition, we refer to these as high-skill and low-skill types, respectively ${ }^{3}$ The ML algorithm suggests that the strongest predictor for occupation choice in the late 1980s is a worker's educational attainment ${ }^{4}$

Table 1 summarizes our findings. Columns (1) and (2) display the of the fraction of workers in-or their propensity to select into-labor force non-participation, unemployment, and employment in NRC, NRM and R occupations for low-skill men. In the late-1980s, the fraction of low-skill types employed in routine occupations was about 0.67 ; by 2017 this had dropped to approximately 0.57 , a 10 percentage point (p.p.) or $16 \log$ point fall.

The decline in routine employment is necessarily accompanied by an offsetting increase in other labor market statuses. Where did these low-skill type men end up in 2017? As indicated by Table 1, they did not go into high-wage NRC occupations, as the propensity to work in NRC remained essentially constant at zero.

By contrast, the probability of non-participation in the labor force (NLF) increased dramatically from 0.17 to 0.24 , and the probability of employment in NRM occupations increased from about 0.11 to 0.15 . These two propensity changes account for the entire fall in R employment. Roughly two-thirds of the decline

\footnotetext{
${ }^{3}$ We choose this delineation for substantive reasons as well: predictive power is high and classification errors are small at this level of aggregation, allowing for the minimization of noise in the type-specific series for employment and occupational choice (see Appendix A.1.2 for further discussion). Moreover, as documented in Cortes (2016) and Cortes, Jaimovich and Siu (2017), large differences in characteristics exist between high- and low-skill worker types, whereas routine (cognitive and manual; simply $\mathrm{R}$ hereafter) and NRM types are much more similar. This motivates previous theoretical analysis (such as the static, labor market models of Autor, Katz and Kearney (2006) and Cortes, Jaimovich and Siu (2017)) as well as our modeling choice below.

${ }^{4}$ See Figure A1 in the Appendix, which displays a heat map of the probability of men in a specific education-age cell to be classified as high-skill. Lower educated men (with high-school diplomas or less) are always classified as low-skill, while those with more education (college graduates) are always classified as high-skill. For men with intermediate levels of education (some post-secondary), there is a gradient by age: younger men tend to sort to non-NRC occupations, older men toward NRC. Race (averaged within each cell) does not play an important role.
} 
Table 1: Labor market status and occupation composition changes for men, 1989-2017 by type

\begin{tabular}{lcccc}
\hline \hline & \multicolumn{2}{c}{ Low-skill } & \multicolumn{2}{c}{ High-Skill } \\
\hline & $(1)$ & $(2)$ & $(3)$ & $(4)$ \\
& 1989 & 2017 & 1989 & 2017 \\
\hline Population Weight & 0.65 & 0.52 & 0.35 & 0.48 \\
\hline Fraction in R & 0.67 & 0.57 & 0.02 & 0.06 \\
Fraction in NRM & 0.11 & 0.15 & $\sim 0$ & 0.01 \\
Fraction in NRC & 0.01 & $\sim 0$ & 0.99 & 0.90 \\
Fraction in NLF & 0.17 & 0.24 & $\sim 0$ & 0.03 \\
Fraction in Unemployment & 0.05 & 0.04 & $\sim 0$ & 0.01 \\
Unemployment rate & 0.06 & 0.06 & $\sim 0$ & 0.01 \\
\hline \hline
\end{tabular}

Notes: The first row of the table reports the share of the population in the non-NRC and NRC groups for men aged 25-64 in 1989 and 2017. Rows 2-6 report the fraction of men in 5 labor market states: Employed in routine occupation (R); Employed in non-routine manual occupation (NRM); Employed in non-routine cognitive occupation (NRC); Not in the labor force (NLF); and unemployed. The last row reports the unemployment rate. The categorization into nonNRC and NRC groups was done using a random forest algorithm (see text for more details). CPS weights are applied in all calculations. 
can be accounted for by the increase in NLF, and the rest by the increase in NRM employment. This is a key result of our analysis: on average, low-skill types leaving $\mathrm{R}$ employment relocate into labor market statuses that are associated with lower income 5 The bottom two rows of Table 1 indicate that the low-skill experienced no obvious change in the unemployment rate, or in their unemployment-to-population ratio ${ }^{6}$

Are these increases in NLF and NRM propensity unique to the low-skilled or are these an economywide phenomena? Columns (3) and (4) of Table 1 summarize the changes in labor force and occupational employment statuses for high-skill men. This group has seen a decrease in NRC employment propensity (see Cortes, Jaimovich and Siu (2018) for analysis of the divergent gender trends in the high-skilled labor market.) But there is very little decline in labor force participation, no change in employment in NRM occupations, and a slight increase in R employment (see Beaudry, Green and Sand (2016) for a model with "crowding in" of high-skilled workers into middle-paying R occupations). This suggests that the changes for the low-skilled are particularly linked to the decline of R occupations.

Women display similar patterns as those of men, but over a different time period. As is well known, the 1960-2000 period saw a pronounced increase in female labor force participation. But since the turn of the twenty-first century, this has plateaued and begun to fall even among the prime-aged. As such, the period since the turn of the century is more indicative of female occupational dynamics.

Columns 1 and 2 of Table 2 present the same information as in Table 1 but for low-skill women, 20012017. There has been a pronounced fall in the likelihood of employment in R occupations, with no increase in the propensity for NRC employment or unemployment $]^{7}$ Instead, they have seen offsetting increases in both the likelihood of non-participation and NRM employment; this split is again roughly two-thirds toward NLF, one-third toward NRM. This is the same split observed for low-skill men over the the 1989-2017 time period, and, as Columns 3 and 4 of Table 2 show, during 2001-2017 as well.

To summarize, the likelihood of working in $\mathrm{R}$ occupations has fallen for those individuals that were likely to be routine workers. This has been offset by increased likelihood of non-participation and NRM employment. In all cases considered, the offsetting labor market changes have been roughly split two-thirds toward non-participation, one-third toward increased employment in low-wage, NRM occupations. We view these "stylized facts" to be important to account for in our quantitative model analysis.

\footnotetext{
${ }^{5}$ Leaving the labor force is likely to be accompanied by increased dependency on transfer payments, while a transition to NRM is likely to be accompanied by a fall in wages and earnings (see, for instance, Autor and Dorn (2013)).

${ }^{6}$ Moreover, using high frequency CPS data we find that within each occupation, both the unemployment rate and exit rates show no low frequency trend over time. Unemployment exit rates were constructed from the outgoing rotation groups in the CPS and are calculated for three type of workers - Routine (R), Non-Routing Manual (NRM) and Non-Routine Cognitive (NRC) based on their last occupation prior to the unemployment spell.

${ }^{7}$ Though not displayed, these dynamics are not observed for high-skill women as neither they are in the case of high-skill men).
} 
Table 2: Labor market status and occupation composition changes for non-NRC types

\begin{tabular}{lcccc}
\hline \hline & \multicolumn{2}{c}{ female } & \multicolumn{2}{c}{ male } \\
\hline & $(1)$ & $(2)$ & $(3)$ & $(4)$ \\
& 2001 & 2017 & 2001 & 2017 \\
\hline Population Weight & 0.68 & 0.55 & 0.58 & 0.52 \\
\hline Fraction in R & 0.39 & 0.30 & 0.64 & 0.57 \\
Fraction in NRM & 0.17 & 0.21 & 0.12 & 0.15 \\
Fraction in NRC & 0.07 & 0.06 & 0.01 & $\sim 0$ \\
Fraction in NLF & 0.34 & 0.40 & 0.19 & 0.24 \\
Fraction in Unemployment & 0.03 & 0.03 & 0.04 & 0.04 \\
Unemployment rate & 0.05 & 0.06 & 0.05 & 0.06 \\
\hline \hline
\end{tabular}

Notes: The first row of the table reports the share of the population in the non-NRC and NRC groups for men aged 25-64 in 1989 and 2017. Rows 2-6 report the fraction of men in 5 labor market states: Employed in routine occupation (R); Employed in non-routine manual occupation (NRM); Employed in non-routine cognitive occupation (NRC); Not in the labor force (NLF); and unemployed. The last row reports the unemployment rate. The categorization into nonNRC and NRC groups was done using a random forest algorithm (see text for more details). CPS weights are applied in all calculations. 


\subsection{Classifying Workers using Cognitive Ability Measures (AFTQ Scores)}

A shortcoming of the ML approach is that it relies on workers' observed educational attainment-a variable that is potentially endogenous to the automation (and potentially other) forces under consideration. To address this, we consider a robustness check using respondent's AFQT score as measured in the National Longitudinal Survey of Youth (NLSY); the AFQT measure is arguably a more direct and exogenous proxy of cognitive ability, determined pre-labor market measure of a worker's type. For comparability of scores between the 1979 and 1997 NLSY surveys, we use the standardized measure provided by Altonji, Bharadwaj and Lange (2012). While the NLSY sample is too small to implement our ML approach, we use it to validate the patterns observed in the CPS.

Our analysis begins with the NLSY79, where we divide the sample into terciles of cognitive ability using the AFQT score and analyze the employment outcomes during 1989-1990. Given the discussion above regarding trends in female participation, we focus our analysis on men. We drop the lowest decile of the AFQT distribution from the analysis, because men in this decile have an extremely low employment rate (below 60\% around age 30).

Table 3 indicates that, conditional on employment, there are large differences in the propensity to work in non-NRC occupation (i.e R or NRM occupations) across AFQT scores. In the first tercile, $82 \%$ of workers were employed in a non-NRC occupation. While less formal, this simple approach classifies men with lower cognitive ability as "low skill."

Table 3: Share of 1979 NLSY men working in Routine or non-Routine Manual occupations in 1989-1990

\begin{tabular}{cccc}
\hline \hline & \multicolumn{4}{c}{ AFQT Deciles } \\
\cline { 2 - 4 } & $2-4$ & $5-7$ & $8-10$ \\
Average share in NRM or R (non-NRC) & 0.82 & 0.68 & 0.47 \\
\cline { 2 - 4 }
\end{tabular}

Notes: The table uses NLSY 1979, to report the share of workers in NRM or R (non-NRC) occupations by deciles of cognitive ability as measured by the AFQT score. For comparability of scores between the 1979 and 1997 NLSY surveys, we use the standardized measure provided by Altonji, Bharadwaj and Lange (2012)

Next, we ask where such workers end up in the post-polarization era. Table 4 compares the labor market status and occupational composition for the low-skilled between 1989-1990 (using the NLSY79) and 2012-2013 (using the NLSY97). The changes in participation and occupational choice for these men (of approximately 30 years of age) are consistent with the pattern from the ML approach using the CPS (for all 
Table 4: Labor market status and occupation composition changes for low cognitive ability men

\begin{tabular}{lcc}
\hline \hline & $1989-1990$ & $2012-2013$ \\
\hline Fraction in R & 0.600 & 0.502 \\
Fraction in NRM & 0.114 & 0.177 \\
Fraction in NRC & 0.157 & 0.134 \\
Fraction in NLF & 0.096 & 0.120 \\
Fraction in Unemployment & 0.033 & 0.060 \\
\hline Average age & 29.35 & 29.69 \\
Observations & 437 & 553 \\
\hline \hline
\end{tabular}

Notes: The table uses NLSY 1979 and NLSY 1997, to report the fraction of workers in the second to fourth decile of cognitive ability in 5 labor market states in 1989-1990 and then again in 2012-2013: Employed in routine occupation (R); Employed in non-routine manual occupation (NRM); Employed in non-routine cognitive occupation (NRC); Not in the labor force (NLF); and unemployed.

prime working ages). There is a large decline in the likelihood of $\mathrm{R}$ employment (again of $16 \%$ as in the CPS analysis above), accompanied by increases in the likelihood of non-participation and NRM employment. The split between these two channels is roughly half-half. That there is greater movement into NRM in the NLSY is not surprising; this sample of low-skill men is younger than the CPS sample, and therefore displays greater labor force attachment.

To summarize, we view this exercise as complementary to the analysis of Section 2.2, indicating the quantitative importance of considering both, selection into labor force participation and occupational choice.

\section{Model}

As discussed above, the fall in the likelihood of working in $\mathrm{R}$, middle-class, occupations could be a result of various factors besides the rise of automation. In order to quantify the role of automation in this fall, we develop a quantitive general equilibrium model with participation and occupational choice. Our view is that the empirical analysis in Section 2 suggests that any model that studies the positive and normative effects of automation should incorporate these dimensions.

Motivated by the findings of Section 2.2 indicating a sharp distinction between NRC and non-NRC types, our model has two types of agents. We refer to these as high-skill (NRC) and low-skill (non-NRC) agents for simplicity. There are three distinct occupations: non-routine cognitive (NRC), routine (R), and non-routine 
manual (NRM).

The low-skilled are heterogeneous as each worker is endowed with two ability parameters (productivity draws from a distribution) —one for occupation R and one for occupation NRM. Given their abilities in each occupation, individuals decide whether to participate in the labor force or not, and conditional on participation, in which occupation to search for employment. The occupational labor markets for low-skill workers are subject to a search and matching friction as in Diamond (1982), Mortensen (1982) and Pissarides (1985). Hence, the low-skill occupation and participation choices depend on job finding probabilities and the equilibrium compensation in each job when employed. While Section 2.2 indicates no change in unemployment across the pre- and post-polarization eras, we model this labor market state since incentive effects on job search and vacancy creation come into consideration in the policy experiments we consider in Section 6.

Capital inputs in the forms of ICT capital and non-ICT capital are used in final production. Both capital stocks are owned by perfectly competitive final good producers who make investment decisions. Hence, the degree of automation in the form of ICT capital accumulation is endogenous (see Eden and Gaggl (2018) who document the rise of ICT capital in the last four decades).

For tractability, we assume that the high-skilled workers are identical, work only in the NRC occupation, and participate in a frictionless labor market. Moreover, again for tractability reasons, we assume that these workers are "capitalists" and own all firm equity in the economy; low-skilled workers are excluded from asset/credit markets and are "hand-to-mouth," with current consumption equal to current income 8 This assumption regarding asset ownership, while simplistic, has empirical traction. For example, the Survey of Consumer Finances (SCF) reports median household net worth by the educational level of household heads. Over the period of 1989-2016, median net worth of college graduates are more than 12 times as large as high school dropouts, and more than 4 times as large as high school graduates. Thus, highly educated individuals, who are empirically NRC worker types (as documented in Section 2.1), own the vast majority of assets in the U.S.

Finally, to allow for analysis of various government policies, we include the following taxes and transfers: a proportional tax on firms' profits, a proportional progressive tax on labor income, unemployment benefits, transfers to labor force non-participants.

\footnotetext{
${ }^{8}$ Allowing all workers to hold assets introduces a number of technical complications. This includes the need to keep track of the marginal owner in the firm's discount factor, the inclusion of wealth in low-skill workers' dynamic problems, and the need to track the distribution of firm ownership/capital holdings.
} 
Before formal presentation of the model, it is useful to comment on its relation to existing work. The basic production structure determining labor demand borrows from the static labor market models of Autor, Katz and Kearney (2006) and Cortes, Jaimovich and Siu (2017). Our analysis is most closely related to Eden and Gaggl (2018) and vom Lehn (2019), who incorporate this labor demand framework into a dynamic, general equilibrium setting.

We build upon them taking key model elements but deviate in two important ways. First, Eden and Gaggl (2018) and vom Lehn (2019) consider representative agent frameworks implying zero consumption and income inequality, making welfare implications of redistributive policies impossible to analyze. We consider a more empirically realistic distribution of income, with high-skilled individuals also being the owners of capital and firms, while low-skilled individuals earn labor income and receive government transfers. In addition, those papers do not model a labor force participation and unemployment margin. Labor supply is inelastic and the choice is along the margin of which occupation to work in, not along the margin of whether to work/seek work. By contrast, individuals in our model are not assumed to work, and may find themselves employed, unemployed, or out of the labor force. This is important for two reasons. First, the empirical analysis above suggested that labor force participation is the key margin of employment adjustment for the routine type workers. Second, allowing for labor force participation and unemployment is critical for the welfare analysis, if one is to consider the implications of policy changes, such as, in transfer payments to labor force non-participants, unemployment insurance, or employment subsidies. Finally, in our framework all government insurance and redistribution programs (e.g., unemployment insurance, and recently discussed proposals for "universal basic income") must be financed through progressive labor and capital/profit taxation. This allows us to use the model as a laboratory for policy evaluation in Section 6.

\subsection{Final Good Producers}

Perfectly competitive, final good firms produce output $(Y)$ using five inputs: intermediate goods (or service flows) produced using NRC, R, and NRM labor denoted $Y_{N R C}, Y_{R}$, and $Y_{N R M}$, respectively; and service flows from ICT capital $\left(X_{A}\right)$ and non-ICT "physical capital" such as structures $(K)$. The constant returns to scale production function for the final good is:

$$
Y_{t}=K_{t}^{\gamma}\left((1-\eta)\left[(1-\alpha) Y_{N R C, t}^{\varsigma_{1}}+\alpha\left[X_{A}^{v}+Y_{R, t}^{v}\right]^{\frac{\varsigma_{1}}{v}}\right]^{\frac{\varsigma_{2}}{\varsigma_{1}}}+\eta Y_{N R M, t}^{\varsigma_{2}}\right)^{\frac{1-\gamma}{\varsigma_{2}}}
$$

where $v$ controls the elasticity of substitution between ICT capital and the R intermediate good, $\varsigma_{1}$ controls the elasticity of substitution between the NRC intermediate good and the ICT-R composite, $\varsigma_{2}$ which controls 
the elasticity of substitution between NRM and the composite of the previously discussed factors, and $\gamma, \eta$ and $\alpha$ control the income shares to different factors of production.

Final good producers accumulate physical and ICT capital (which depreciate at rates $\delta_{K}$ and $\delta_{A}$, respectively) and purchase the three intermediate goods from competitive markets at prevailing prices 99 The relative price of investment in non-ICT is denoted $\phi_{K}$ and the relative price of ICT capital is $\phi_{A}$, where the final good is the numeraire $\left(P_{Y}=1\right)$. Hence, denoting by the "prime notation" a next period's variable, the firm's per-period profit is:

$$
\pi=Y-P_{R} Y_{R}-P_{N R M} Y_{N R M}-P_{N R C} Y_{N R C}-\phi_{A}\left(X_{A}^{\prime}-\left(1-\delta_{A}\right) X_{A}\right)-\phi_{K}\left(K^{\prime}-\left(1-\delta_{K}\right) K\right)
$$

with the prices of intermediate goods given by $P_{R}, P_{N R C}, P_{N R M}$. The firm's dynamic problem is:

$$
V\left(K, X_{A}, \Lambda\right)=\max _{K^{\prime}, X_{A}^{\prime}, Y_{R}, Y_{N R M}, Y_{N R C}}\left\{\left(1-T_{\pi}\right) \pi+\beta\left[V\left(K^{\prime}, X_{A}^{\prime}, \Lambda^{\prime}\right)\right]\right\}
$$

where $T_{\pi}$ is a tax rate on firms' profits, $\beta$ is the discount factor, and $\Lambda=\left\{\phi_{K}, \phi_{A}, T_{\pi}, P_{R}, P_{N R M}, P_{N R C}\right\}$ is a vector that contains all the state variables that the representative firm takes as given, which are either exogenously specified or determined in equilibrium. Moreover, since our analysis below is across steady states we already impose the stochastic discount factor being equal to $\beta{ }^{10}$

The firm accumulates physical and ICT capital in accordance with two standard Euler equations that equalize marginal cost and future return:

$$
\begin{gathered}
\phi_{K}=\beta\left[M P K^{\prime}+\left(1-\delta_{K}\right) \phi_{K}^{\prime}\right] \\
\phi_{A}=\beta\left[M P A^{\prime}+\left(1-\delta_{A}\right) \phi_{A}^{\prime}\right]
\end{gathered}
$$

where $M P K$ and MPA denote the marginal products of the two types of capital. Because profits are taxed net of investment costs, there are no equilibrium effects on optimal capital demand 11

\footnotetext{
${ }^{9}$ The model is isomorphic if we assume that the final good firm also rents the capital from intermediate capital services producers.

${ }^{10}$ In writing the firm's problem this way we already impose consistency conditions such that the optimal choice is identical across firms and therefore represents the aggregate. As we show below, prices of intermediate goods are determined by the optimal demand and therefore by aggregate quantities of the intermediate goods.

${ }^{11}$ For a a similar approach see Abel (2007).
} 


\subsection{Intermediate Goods Production}

\subsubsection{Routine Intermediate Good Producers}

Intermediate good producers produce the routine intermediate good, $Y_{R}$ and sell it to the final good firm. In order to produce the routine intermediate good these producers recruit routine workers in a frictional labor market. As we discuss below, each low-skill agent is endowed with a pair of idiosyncratic productivity parameters, $\varepsilon_{R}$ and $\varepsilon_{N R M}$, drawn from a joint distribution $\Gamma\left(\varepsilon_{R}, \varepsilon_{N R M}\right) ; \varepsilon_{R}\left(\varepsilon_{N R M}\right)$ denotes the idiosyncratic ability of the worker if employed in production of the R (NRM) intermediate good. We assume that the labor markets for the low-skilled are frictional and fully segmented by good $i$ and ability $\varepsilon$. That is, there is full information about worker abilities allowing unemployed workers and vacancies to meet in occupationand-ability-specific matches.

Generally, this setup implies that within each occupation, wages are specific for each combination of $\varepsilon_{R}$ and $\varepsilon_{N R M}$. However, as discussed in Section (4), our quantitative analysis will focus on steady state equilibrium, implying that there are no transitions across occupations (only between employment and unemployment states within an occupation). Thus, in this case, the bargained wage of an individual, within a given occupation, is not a function of her productivity in the other occupation. To avoid cluttered notation, we introduce the firm decision problem assuming steady state wages, thus using $\omega_{R, \varepsilon_{R}}$ and $\omega_{R, \varepsilon_{N R M}}$ to represent wages paid for $\mathrm{R}$ workers with ability $\varepsilon_{R}$ and for NRM workers with ability $\varepsilon_{N R M}$ respectively.

Hence, hiring low-skill workers with idiosyncratic ability $\varepsilon_{R}$ (if these individuals endogenously decide to work in the $\mathrm{R}$ occupation in equilibrium) to produce routine intermediate goods requires a firm to post vacancies, $v_{\varepsilon_{R}}$, at flow cost of $\kappa_{\varepsilon_{R}}$ per vacancy. A constant returns to scale matching function, $M\left(v_{\varepsilon_{R}}, u_{\varepsilon_{R}}\right)$, determines the number of new matches given vacancies and the number of unemployed job searchers $\left(u_{\varepsilon_{R}}\right)$ in this good-ability-specific market. As is standard in the literature, firms take the tightness ratio, $\theta_{\varepsilon_{R}} \equiv \frac{v_{\varepsilon_{R}}}{u_{\varepsilon_{R}}}$, and the vacancy filling probability $q\left(\theta_{R, \varepsilon_{R}}\right)$ as given.

A matched firm and worker (with ability $\varepsilon_{R}$ ) produce $y_{\varepsilon_{R}}=f_{R} \varepsilon_{R}$ units of the $\mathrm{R}$ good, where $f_{R}$ is an identical productivity parameter across all matches irrespective of $\varepsilon_{R}$. This intermediate good is sold to the final good producer at the competitive price $P_{R}$ per unit. The firm pays a bargained wage $\omega_{R, \varepsilon_{R}}$ to the worker. Thus the flow profit from a match is $P_{R} f_{R} \varepsilon_{R}-\omega_{R, \varepsilon_{R}}$.

Let $x_{\varepsilon_{R}}$ denote the number of employed $\mathrm{R}$ workers with idiosyncratic productivity $\varepsilon_{R}$. To derive the optimality condition for vacancy creation, we assume - for expositional clarity - that there exists a representative good-ability-specific firm that chooses $v_{\varepsilon_{R}}$ to solve:

$$
J\left(x_{\varepsilon_{R}}, \Lambda\right)=\max _{v_{\varepsilon_{R}}}\left\{\left(1-T_{\pi}\right)\left[x_{\varepsilon_{R}}\left(P_{R} f_{R} \varepsilon_{R}-\omega_{\varepsilon_{R}}\right)-\kappa_{\varepsilon_{R}} v_{\varepsilon_{R}}\right]+\beta\left[J\left(x_{\varepsilon_{R}}^{\prime}, \Lambda^{\prime}\right)\right]\right\}
$$


subject to the law of motion:

$$
x_{\varepsilon_{R}}^{\prime}=(1-\delta) x_{\varepsilon_{R}}+v_{\varepsilon_{R}} q\left(\theta_{\varepsilon_{R}}\right) .
$$

Here $\delta$ is the exogenous match separation probability (that is common across good-ability-specific matches). The first order condition implies the optimality condition for vacancy posting: 12

$$
\frac{\kappa_{\varepsilon_{R}}}{q\left(\theta_{\varepsilon_{R}}\right)}=\beta\left[P_{R} f_{R} \varepsilon_{R}-\omega_{\varepsilon_{R}}+(1-\delta) \frac{\kappa_{\varepsilon_{R}}}{q\left(\theta_{\varepsilon_{R}}^{\prime}\right)}\right] .
$$

As with the case of capital taxation, because firm profits are taxed net of vacancy costs, there are no equilibrium effects of profit taxation on low-skilled job creation.

The quantity of efficiency-weighted R labor input is then given by:

$$
Y_{R}=f_{R}\left(1-\operatorname{Pop}_{N R C}\right) \int_{\varepsilon_{R}^{*}}^{\infty} \int_{-\infty}^{\varepsilon_{N R M}\left(\varepsilon_{R}\right)} E R_{\varepsilon_{R}} \varepsilon_{R} \Gamma^{\prime}\left(\varepsilon_{R}, \varepsilon_{N R M}\right) d \varepsilon_{N R M} d \varepsilon_{R},
$$

where $P o p_{N R C}$ denotes the population share of high-skilled workers, $\Gamma^{\prime}\left(\varepsilon_{R}, \varepsilon_{N R M}\right)$ denotes the density function associated with the distribution function, $\Gamma$, and $E R_{\varepsilon_{R}}=\frac{x_{\varepsilon_{R}}}{\left(x_{\varepsilon_{R}}+u_{\varepsilon_{R}}\right)}$ denotes the employment rate (per labor force participant) for a given ability level, $\varepsilon_{R}$ (recall that $x_{\varepsilon_{R}}$ denotes the measure of individuals with ability $\varepsilon_{R}$ that are working while $u_{\varepsilon_{R}}$ denotes the measure of individuals with ability $\varepsilon_{R}$ who are unemployed).

As we show in Section 4.2, the economy is characterized by an ability cutoff in the R and NRM occupational abilities as well as a function that determines in which occupation a worker works conditional on participating in the labor force. In Equation (4) the term $\varepsilon_{R}^{*}$ denotes the cutoff ability in $\mathrm{R}$ such that all those with lesser ability do not work in R; the function $\varepsilon_{N R M}\left(\varepsilon_{R}\right)$ denotes the cutoff in ability NRM for each $\varepsilon_{R}$ value such that below it, workers choose to work in R and not in NRM.

\subsubsection{Non-Routine Manual Intermediate Good Producers}

The labor market for the NRM occupation is identical in structure to the R occupation and obeys the same optimality principles. We do not repeat the exposition for brevity, and simply present the vacancy posting

\footnotetext{
${ }^{12}$ The use of a representative firm is for convenience only. An identical optimal condition can be derived when assuming a Bellman value for an open vacancy, a Bellman value for a filled job, and a zero profit condition:

$$
\begin{aligned}
& V_{R, \varepsilon_{R}}=-\left(1-T_{\pi}\right) \kappa_{R, \varepsilon_{R}}+q\left(\theta_{R, \varepsilon_{R}}\right) \beta\left[J_{R, \varepsilon_{R}}^{\prime}\right]=0, \\
& J_{R, \varepsilon_{R}}=\left(1-T_{\pi}\right)\left[f_{R} \varepsilon_{R} P_{R}-\omega_{R, \varepsilon_{R}}\right]+(1-\delta) \beta\left[J_{R, \varepsilon_{R}}^{\prime}\right] .
\end{aligned}
$$
}


optimality condition:

$$
\frac{\kappa_{\varepsilon_{N R M}}}{q\left(\theta_{\varepsilon_{N R M}}\right)}=\beta\left[P_{N R M} f_{N R M} \varepsilon_{N R M}-\omega_{\varepsilon_{N R M}}+(1-\delta) \frac{\kappa_{\varepsilon_{N R M}}}{q\left(\theta_{\varepsilon_{N R M}}^{\prime}\right)}\right] .
$$

In equilibrum, the quantity of efficiency-weighted NRM labor input is given by:

$$
Y_{N R M}=f_{N R M}\left(1-\operatorname{Pop}_{N R C}\right) \int_{\varepsilon_{N R M}^{*}}^{\infty} \int_{-\infty}^{\varepsilon_{R}\left(\varepsilon_{N R M}\right)} E R_{\varepsilon_{N R M}} \varepsilon_{N R M} \Gamma^{\prime}\left(\varepsilon_{R}, \varepsilon_{N R M}\right) d \varepsilon_{R} d \varepsilon_{N R M}
$$

where $E R_{\varepsilon_{N R M}}=\frac{x_{\varepsilon_{N R M}}}{\left(x_{\varepsilon_{N R M}}+u_{\varepsilon_{N R M}}\right)}$.

\subsubsection{Non-Routine Cognitive Intermediate Good Producers}

Given our primary interest is in the low-skilled labor market, we assume for simplicity that the high-skilled labor market has no matching frictions. High-skill workers make no occupational choice, work only in NRC production, and are identical in ability (normalized to unity). The problem of the NRC intermediate good producer is static:

$$
\max _{x_{N R C}} f_{N R C} P_{N R C} x_{N R C}-\omega_{N R C} x_{N R C}
$$

taking productivity, $f_{N R C}$, and competitively determined prices, $P_{N R C}$ and $\omega_{N R C}$ as given. This gives rise to the simple marginal revenue product equals wage condition in equilibrium:

$$
\omega_{N R C}=f_{N R C} P_{N R C}
$$

\subsection{Workers}

In this subsection, we describe the dynamic optimization problem of high-skill and low-skill workers. All workers are infinitely-lived and discount the future at rate $0<\beta<1$.

\subsubsection{Non-Routine Cognitive Workers}

The results of Section 2.1 indicate that the high-skilled experience experience very low unemployment which has not changed over time. Given this, we abstract from search-and-matching frictions. Our ultimate interest is in accounting for general equilibrium effects of various policy proposals, that must be financed through (progressive) distortionary income taxation. Given this, we opt to capture these distortions in the simplest way; specifically, we model a labor supply margin of hours worked choice by the high-skilled that responds to variation in the distortionary tax rate.

Formally, an exogenously specified fraction of workers are high-skill (NRC) workers, who have preferences over consumption, $C_{N R C}$ denoted by the utility $U\left(C_{N R C}\right)$, and derive disutility from hours spent 
working, $L_{N R C}$ denoted by $G\left(L_{N R C}\right){ }^{13}$ They earn $\omega_{N R C}$ per hour worked and are taxed on labor income at the rate $T_{N R C}$. High-skill workers save in the form of an asset that represents claims to profits of intermediate goods firms. Let $B_{N R C}$ denote the beginning of period value of such claims (the sum of dividends and resale value) that are traded at price $p$. Then, NRC workers solve:

$$
\begin{aligned}
& V_{N R C}\left(B_{N R C}, \Lambda\right)=\max _{C_{N R C}, B^{\prime}}\left\{U\left(C_{N R C}\right)-G\left(L_{N R C}\right)+\beta\left[V_{N R C}\left(B_{N R C}^{\prime}, \Lambda^{\prime}\right)\right]\right\} \\
& \text { s.t.: } C_{N R C}+p B_{N R C}^{\prime}=L_{N R C} \omega_{N R C}\left(1-T_{N R C}\right)+p B_{N R C}
\end{aligned}
$$

\subsubsection{Routine and Non-Routine Manual Workers}

Let $\left(\varepsilon_{R}, \varepsilon_{N R M}\right)$ denote a worker's (constant) idiosyncratic ability draw pair. Given these draws an unmatched low-skill worker simultaneously chooses whether to participate in the labor market or not and, conditional on participating, in which occupational labor market to search. Let $V_{e, \varepsilon_{R}, \varepsilon_{N R M}}(\Lambda)$ denote the value of being an employed $\mathrm{R}$ worker for a worker with the productivities $\left(\varepsilon_{R}, \varepsilon_{N R M}\right)$; for simplicity we denote the chosen occupation for such an individual by the first subscript of the two productivities draw. Then, similarly, $V_{u, \varepsilon_{R}, \varepsilon_{N R M}}(\Lambda)$ denotes the value of being an unemployed $\mathrm{R}$ worker for such an individual, $V_{e, \varepsilon_{N R M}, \varepsilon_{R}}(\Lambda)$ the value of being an employed NRM worker for this individual, and $V_{u, \varepsilon_{N R M}, \varepsilon_{R}}(\Lambda)$ is the value of being an unemployed NRM worker for this individual. Let the value of labor force non-participation be $V_{\varepsilon_{O}}(\Lambda)$, where we remind the reader that $\Lambda=\left\{\phi_{K}, \phi_{A}, T_{\pi}, P_{R}, P_{N R M}, P_{N R C}\right\}$, denoting the collection of aggregate state variables that workers take parametrically.

The value of being employed as an $\mathrm{R}$ worker is then given by:

$$
\begin{aligned}
V_{e, \varepsilon_{R}, \varepsilon_{N R M}}(\Lambda)= & U\left(C_{e, \varepsilon_{R}}\right)+\beta \delta\left[\max \left\{V_{u, \varepsilon_{R}, \varepsilon_{N R M}}\left(\Lambda^{\prime}\right), V_{u, \varepsilon_{N R M}, \varepsilon_{R}}\left(\Lambda^{\prime}\right), V_{\varepsilon_{O}}\left(\Lambda^{\prime}\right)\right\}\right]+ \\
& \beta(1-\delta)\left[\max \left\{V_{e, \varepsilon_{R}, \varepsilon_{N R M}}\left(\Lambda^{\prime}\right), V_{u, \varepsilon_{R}, \varepsilon_{N R M}}\left(\Lambda^{\prime}\right), V_{u, \varepsilon_{N R M}, \varepsilon_{R}}\left(\Lambda^{\prime}\right), V_{\varepsilon_{O}}\left(\Lambda^{\prime}\right)\right\}\right] .
\end{aligned}
$$

Current period consumption, $C_{e, \varepsilon_{R}}$, must satisfy the budget constraint:

$$
C_{e, \varepsilon_{R}}=\omega_{\varepsilon_{R}}\left(1-T_{\varepsilon_{R}}\right)
$$

where $\omega_{\varepsilon_{R}}$ denotes the wage (low-skill workers supply one unit of labor inelastically when employed), and $T_{\varepsilon_{R}}$ is the income tax rate.

Routine matches separate with exogenous probability $\delta$. If the match separates, the worker chooses whether to leave or remain in the labor force in the following period; in the latter case, the worker also

\footnotetext{
${ }^{13}$ For exposition clarity we assume separability in consumption and leisure as we assume this formulation in our quantitative work.
} 
chooses whether to search for employment in the R or NRM occupation. If the match does not separate, the worker has the choice of remaining matched in the following period, leaving to unemployment, or leaving the labor force. Given our interest in steady state comparison, an employed worker will never switch from employment in one other sector to another.

An unemployed worker searching for a match in the $\mathrm{R}$ occupation meets a vacancy with probability $\mu\left(\theta_{\varepsilon_{R}}\right)$. Upon meeting, the worker chooses whether to match and become employed, remain unmatched/unemployed, or leave the labor force. The dynamic problem of an unemployed worker is:

$$
\begin{aligned}
V_{u, \varepsilon_{R}, \varepsilon_{N R M}}(\Lambda)= & U\left(C_{u, \varepsilon_{R}}\right)+\beta\left(1-\mu\left(\theta_{\varepsilon_{R}}\right)\right)\left[\max \left\{V_{u, \varepsilon_{R}, \varepsilon_{N R M}}\left(\Lambda^{\prime}\right), V_{u, \varepsilon_{N R M}, \varepsilon_{R}}\left(\Lambda^{\prime}\right), V_{\varepsilon_{O}}\left(\Lambda^{\prime}\right)\right\}\right]+ \\
& \beta \mu\left(\theta_{\varepsilon_{R}}\right)\left[\max \left\{V_{e, \varepsilon_{R}, \varepsilon_{N R M}}\left(\Lambda^{\prime}\right), V_{u, \varepsilon_{R}, \varepsilon_{N R M}}\left(\Lambda^{\prime}\right), V_{u, \varepsilon_{N R M}, \varepsilon_{R}}\left(\Lambda^{\prime}\right), V_{\varepsilon_{O}}\left(\Lambda^{\prime}\right)\right\}\right],
\end{aligned}
$$

subject to:

$$
C_{u, \varepsilon_{R}}=b \omega_{\varepsilon_{R}}
$$

where $b$ denotes the (net of tax) unemployment insurance replacement rate for a worker with $\mathrm{R}$ ability, $\varepsilon_{R}$. The problem for workers who are employed in, or unemployed and choose to search in, the NRM occupation is identical in structure to that just described, except with R-subscripts replaced by NRM-subscripts and vice versa.

A worker who is out of the labor force chooses whether to remain a non-participant, or become unemployed in either R or NRM. We assume that the transfer to labor force non-participants is constant and independent of ability. Hence, the dynamic problem is:

$$
V_{\varepsilon_{O}}(\Lambda)=U\left(C_{O}\right)+\beta\left[\max \left\{V_{u, \varepsilon_{R}, \varepsilon_{N R M}}\left(\Lambda^{\prime}\right), V_{u, \varepsilon_{N R M}, \varepsilon_{R}}\left(\Lambda^{\prime}\right), V_{\varepsilon_{O}}\left(\Lambda^{\prime}\right)\right\}\right]
$$

subject to:

$$
C_{o}=b_{o}
$$

Here, $b_{o}$ denotes (net of tax) government transfers to non-participants. Although non-participants receive the same income, they have different abilities, $\varepsilon$, and face differing likelihoods of labor force participation following a change in the economy.

\subsection{Wage Bargaining}

A match between an intermediate good firm and a worker generates a positive surplus that must be split. As is common in the literature, we assume the Nash bargaining solution to surplus division. We present the Nash bargaining problem for an R match; the exposition for an NRM match is analogous. 
The surplus for a firm is the marginal value of employing an additional worker:

$$
\frac{\partial J\left(x_{\varepsilon_{R}}, \Lambda\right)}{\partial x_{\varepsilon_{R}}}=\left(1-T_{\pi}\right)\left(f_{R} \varepsilon_{R} P_{R}-\omega_{\varepsilon_{R}}\right)+(1-\delta) \beta\left[\frac{\partial J\left(x_{\varepsilon_{R}}^{\prime}, \Lambda^{\prime}\right)}{\partial x_{\varepsilon_{R}}^{\prime}}\right] .
$$

The surplus for an employed worker with idiosyncratic ability $\varepsilon_{R}$ is:

$$
\tilde{V}_{\varepsilon_{R}}(\Lambda)=V_{e, \varepsilon_{R}, \varepsilon_{N R M}}(\Lambda)-\left[\max \left\{V_{u, \varepsilon_{R}, \varepsilon_{N R M}}(\Lambda), V_{u, \varepsilon_{N R M}, \varepsilon_{R}}(\Lambda), V_{\varepsilon_{O}}(\Lambda)\right\}\right]
$$

The worker's outside option is the optimal choice across searching for a new match in either the R or NRM occupation, or labor force non-participation.

Denoting the worker's bargaining weight by $\tau$ and the firm's by $1-\tau$, the wage for a worker employed in R with ability $\varepsilon_{R}$ is the solution to:

$$
\max _{\omega_{\varepsilon_{R}}}\left[\tilde{V}_{\varepsilon_{R}}(\Lambda)\right]^{\tau}\left[\frac{\partial J\left(x_{\varepsilon_{R}}, \Lambda\right)}{\partial x_{\varepsilon_{R}}}\right]^{1-\tau}
$$

In Section 4 we impose functional form assumptions that allow for an analytic solution for the resulting wage function.

\subsection{Government Budget Constraint}

Total unemployment insurance transfers to low-skill workers searching for NRM employment is given by:

$$
U I_{N R M}=\left(1-P_{o p} p_{N R C}\right) \int_{\varepsilon_{N R M}^{*}}^{\infty} \int_{-\infty}^{\varepsilon_{R}\left(\varepsilon_{N R M}\right)} U R_{\varepsilon_{N R M}} b \omega_{\varepsilon_{N R M}} \Gamma^{\prime}\left(\varepsilon_{R}, \varepsilon_{N R M}\right) d \varepsilon_{R} d \varepsilon_{N R M},
$$

where $U R_{\mathcal{E}_{N R M}}=1-E R_{\mathcal{\varepsilon}_{N R M}}=\frac{u_{\varepsilon_{N R M}}}{\left(x_{\varepsilon_{N R M}}+u_{\varepsilon_{N R M}}\right)}$ is the unemployment rate at ability level $\varepsilon_{N R M}$. Similarly, transfers to unemployed $\mathrm{R}$ workers is:

$$
U I_{R}=\left(1-\operatorname{Pop}_{N R C}\right) \int_{\varepsilon_{R}^{*}}^{\infty} \int_{-\infty}^{\varepsilon_{N R M}\left(\varepsilon_{R}\right)} U R_{\varepsilon_{N R M}} b \omega_{\varepsilon_{R}} \Gamma^{\prime}\left(\varepsilon_{R}, \varepsilon_{N R M}\right) d \varepsilon_{N R M} d \varepsilon_{R},
$$

where $U R_{\varepsilon_{R}}=1-E R_{\varepsilon_{R}}=\frac{u_{\varepsilon_{R}}}{\left(x_{\varepsilon_{R}}+u_{\varepsilon_{R}}\right)}$. Letting $N L F$ denote the measure of low-skill workers outside the labor force:

$$
N L F=\int_{-\infty}^{\varepsilon_{R}^{*}} \int_{-\infty}^{\varepsilon_{N R M}^{*}} \Gamma^{\prime}\left(\varepsilon_{R}, \varepsilon_{N R M}\right) d \varepsilon_{N R M} d \varepsilon_{R},
$$

total government transfers to this group is $N L F b_{o}$.

Government revenues are derived from labor and profit taxation. Labor taxes collected from employed NRM and $\mathrm{R}$ workers is given by:

$$
\operatorname{Rev}_{N R M}=\left(1-P o p_{N R C}\right) \int_{\varepsilon_{N R M}^{*}}^{\infty} \int_{-\infty}^{\varepsilon_{R}\left(\varepsilon_{N R M}\right)} E R_{\varepsilon_{N R M}} T_{\varepsilon_{N R M}} \omega_{\varepsilon_{N R M}} \Gamma^{\prime}\left(\varepsilon_{R}, \varepsilon_{N R M}\right) d \varepsilon_{R} d \varepsilon_{N R M}
$$


and :

$$
\operatorname{Rev}_{R}=\left(1-\operatorname{Pop}_{N R C}\right) \int_{\varepsilon_{R}^{*}}^{\infty} \int_{-\infty}^{\varepsilon_{N R M}\left(\varepsilon_{R}\right)} E R_{\varepsilon_{R}} T_{\varepsilon_{R}} \omega_{\varepsilon_{R}} \Gamma^{\prime}\left(\varepsilon_{R}, \varepsilon_{N R M}\right) d \varepsilon_{N R M} d \varepsilon_{R},
$$

respectively. Labor taxes collected from NRC workers is:

$$
\operatorname{Rev}_{N R C}=\operatorname{Pop}_{N R C} L_{N R C} \omega_{N R C} T_{N R C}
$$

Revenue from the tax on profits of intermediate producers in the NRM and R occupations is given by:

$$
\begin{gathered}
\operatorname{Rev}_{\pi_{N R M}}=\left(T_{\pi}\right)\left(1-\operatorname{Pop}_{N R C}\right) \int_{\varepsilon_{N R M}^{*}}^{\infty} \int_{-\infty}^{\varepsilon_{R}\left(\varepsilon_{N R M}\right)}\left[x_{\varepsilon_{N R M}}\left(f_{\varepsilon_{N R M}} \varepsilon_{\varepsilon_{N R M}} P_{N R M}-\omega_{\varepsilon_{N R M}}\right)-\kappa_{\varepsilon_{N R M}} v_{\varepsilon_{N R M}}\right] \Gamma^{\prime}\left(\varepsilon_{R}, \varepsilon_{N R M}\right) d \varepsilon_{R} d \varepsilon_{N R M}, \\
\operatorname{Rev}_{\pi_{R}}=\left(T_{\pi}\right)\left(1-\operatorname{Pop}_{N R C}\right) \int_{\varepsilon_{R}^{*}}^{\infty} \int_{-\infty}^{\varepsilon_{N R M}\left(\varepsilon_{R}\right)}\left[x_{\varepsilon_{R}}\left(f_{R} \varepsilon_{R} P_{R}-\omega_{\varepsilon_{R}}\right)-\kappa_{\varepsilon_{R}} v_{\varepsilon_{R}}\right] \Gamma^{\prime}\left(\varepsilon_{R}, \varepsilon_{N R M}\right) d \varepsilon_{N R M} d \varepsilon_{R}
\end{gathered}
$$

Tax revenue from the final good producer is given by:

$$
\operatorname{Rev}_{\pi}=T_{\pi}\left[Y-P_{R} Y_{R}-P_{N R M} Y_{N R M}-P_{N R C} Y_{N R C}-\phi_{A}\left(X_{A}^{\prime}-\left(1-\delta_{A}\right) X_{A}\right)-\phi_{K}\left(K^{\prime}-\left(1-\delta_{K}\right) K\right)\right]
$$

The government does not borrow or save, so that at each point in time the following budget constraint holds:

$$
N L F b_{o}+U I_{N R M}+U I_{R}=R e v_{N R C}+\operatorname{Rev}_{R}+\operatorname{Rev}_{N R M}+\operatorname{Rev}_{\pi}+\operatorname{Rev}_{\pi_{R}}+\operatorname{Rev}_{\pi_{N R M}}
$$

\subsection{Equilibrium}

To summarize the structure of the model, an exogenously specified fraction of workers are high-skilled. They supply their labor in a frictionless labor market to the the NRC intermediate good and receive a market wage equal to their marginal revenue product.

With respect to low-skilled individuals, each low-skill agent is endowed with a pair of idiosyncratic productivity parameters, $\varepsilon_{R}$ and $\varepsilon_{N R M}$, drawn from a joint distribution $\Gamma\left(\varepsilon_{R}, \varepsilon_{N R M}\right)$. The labor markets for the low-skilled are frictional and fully segmented by good $i$ and ability $\varepsilon_{i}$, for $i=\{R, N R M\}$.

Unemployed low-skill workers choose whether to search in the R or NRM labor market or to leave the labor force. Low-skill workers work for profit-maximizing intermediate producers. Producers decide whether to maintain vacancies and, if so, in which good-and-ability specific market. Given equilibrium prices, outside options, and government policies, intermediate good firms choose vacancies optimally. Free entry implies zero lifetime profits.

Hence, formally, given productivities, $\left\{Z, \phi_{K}, \phi_{A} f_{R}, f_{N R M}, f_{N R C}\right\}$, the distribution of low-skill abilities, $\Gamma\left(\varepsilon_{R}, \varepsilon_{N R M}\right)$, and the population fraction of high-skill workers, $P o p_{N R C}$, a symmetric stationary equilibrium with Nash bargaining is a collection of: 
- intermediate good prices, $\left\{P_{N R C}, P_{R}, P_{N R M}\right\}$, and prices on equity claims $\{p\}$;

- wages $\left\{\omega_{N R C}\right\}$ and $\left\{\omega_{\varepsilon_{R}}, \omega_{\varepsilon_{N R M}}\right\}$ for all $\varepsilon_{R}, \varepsilon_{N R M}$;

- tightness ratios, $\left\{\theta_{\varepsilon_{R}}, \theta_{\varepsilon_{N R M}}\right\}$, and vacancies, $\left\{v_{\varepsilon_{R}}, v_{\mathcal{E}_{N R M}}\right\}$, for all $\varepsilon_{R}, \varepsilon_{N R M}$;

- worker quantities, $\left\{C_{N R C}, L_{N R C}, B_{N R C}, C_{o}\right\}$ and $\left\{C_{e, \varepsilon_{R}}, C_{u, \varepsilon_{R}}, C_{e, \varepsilon_{N R M}}, C_{u, \varepsilon_{N R M}}\right\}$ for all $\varepsilon_{R}, \varepsilon_{N R M}$;

- labor input, $x_{N R C}$ and $\left\{x_{\varepsilon_{R}}, x_{\varepsilon_{N R M}}\right\}$ for all $\varepsilon_{R}, \varepsilon_{N R M}$;

- firm quantities, $\left\{Y, Y_{N R C}, Y_{R}, Y_{N R M}, K, X_{A}\right\}$; and

- policy, $\left\{T_{\pi}, T_{N R C}, b, b_{o}\right\}$ and $\left\{T_{\varepsilon_{R}}, T_{\varepsilon_{N R M}}\right\}$ for all $\varepsilon_{R}, \varepsilon_{N R M}$

such that

- final good and intermediate good firms are profit maximizing (and in particular, physical capital accumulation, automation capital accumulation, and vacancy creation is optimal),

- workers are utility maximizing (specifically, high-skill workers are making saving and labor supply decisions, and low-skill workers are making participation and occupational choices optimally),

- $R$ and $N R M$ wages solve their respective Nash bargaining problems,

- the final good market clears:

$$
\begin{aligned}
Y=\operatorname{Pop}_{N R C} C_{N R C} & +\left(1-\operatorname{Pop}_{N R C}\right)\left[\int_{\varepsilon_{R}^{*}}^{\infty} \int_{-\infty}^{\varepsilon_{N R M}\left(\varepsilon_{R}\right)}\left(E R_{\varepsilon_{R}} C_{e, \varepsilon_{R}}+U R_{\varepsilon_{R}} C_{u, \varepsilon_{R}}+\kappa_{\varepsilon_{R}} v_{\varepsilon_{R}}\right) \Gamma^{\prime}\left(\varepsilon_{R}, \varepsilon_{N R M}\right) d \varepsilon_{N R M} d \varepsilon_{R}\right. \\
& +\int_{\varepsilon_{N R M}^{*}}^{\infty} \int_{-\infty}^{\varepsilon_{R}\left(\varepsilon_{N R M}\right)}\left(E R_{\mathcal{E}_{N R M}} C_{e, \varepsilon_{N R M}}+U R_{\varepsilon_{N R M}} C_{u, \varepsilon_{N R M}}+\kappa_{\varepsilon_{N R M}} v_{\varepsilon_{N R M}}\right) \Gamma^{\prime}\left(\varepsilon_{R}, \varepsilon_{N R M}\right) d \varepsilon_{R} d \varepsilon_{N R M} \\
& \left.+\int_{-\infty}^{\varepsilon_{R}^{*}} \int_{-\infty}^{\varepsilon_{N R M}^{*}} C_{o} \Gamma^{\prime}\left(\varepsilon_{R}, \varepsilon_{N R M}\right) d \varepsilon_{N R M} d \varepsilon_{R}\right]+\phi_{A}\left(X_{A}^{\prime}-\left(1-\delta_{A}\right) X_{A}\right)+\phi_{K}\left(K^{\prime}-\left(1-\delta_{K}\right) K\right)
\end{aligned}
$$

- labor market of the three factors of production clears,

- the equity market clears: $B=1$, and

- the government's budget constraint is satisfied. 


\section{Construction of Steady State Equilibrium}

In this section we characterize the steady state equilibrium. We highlight a set of sufficient assumptions that deliver, as in the data, unemployment rates that do not vary as ICT price fall. The three conditions are: (i) a constant relative risk aversion (hereafter CRRA) function, $U($.$) , (ii) vacancy costs, \kappa_{\varepsilon_{R}}, \kappa_{\varepsilon_{N R M}}$ for all $\varepsilon_{R}, \varepsilon_{N R M}$, that are proportional to productivity, and (iii) income for low-skill labor force participants that is proportional to their wage (i.e., unemployment benefits specified as a replacement rate relative to the wage when employed) as modelled above.

\subsection{Wages and tightness ratios}

Recall the bargaining problem characterizing the $\mathrm{R}$ occupation, equation (5). As we show in Appendix $\mathrm{A} .2 .1$, the resulting wage for an $\mathrm{R}$ worker with ability $\varepsilon_{R}$ is:

$$
\omega_{\varepsilon_{R}}=f_{R} \varepsilon_{R} P_{R}-\frac{1-\tau}{\tau} \frac{U\left(C_{e, \varepsilon_{R}}\right)-U\left(C_{u, \varepsilon_{R}}\right)}{U^{\prime}\left(C_{e, \varepsilon_{R}}\right)\left(1-T_{\varepsilon_{R}}\right)-U^{\prime}\left(C_{u, \varepsilon_{R}}\right) b}+\theta_{\varepsilon_{R}} \kappa_{\varepsilon_{R}}
$$

This is an increasing function of the worker's marginal revenue product, $f_{R} \varepsilon_{R} P_{R}$, as well as labor market tightness, $\theta_{\varepsilon_{R}}$, which reflects the outside option for the worker. Unlike the standard DMP model with risk neutrality, the wage is also affected by the utility and marginal utility differences between employed and unemployed workers.

With an eye toward quantitative analysis, we assume a CRRA utility function, $U(C)=\frac{C^{1-\sigma}}{1-\sigma}$. We show in Appendix A.2.1 that the wage function simplifies to:

$$
\omega_{\varepsilon_{R}}=\frac{1}{1+\Psi}\left[f_{R} \varepsilon_{R} P_{R}+\theta_{R, \varepsilon_{R}} \kappa_{R, \varepsilon_{R}}\right]
$$

where $\Psi=\frac{(1-\tau)}{\tau(1-\sigma)}$. By following Pissarides (2000) and assuming that the hiring cost, $\kappa_{\varepsilon_{R}}$, is proportional to the worker's ability (reflecting the idea that it is more costly to hire more productive workers), i.e.,

$$
\kappa_{\varepsilon_{R}}=f_{R} P_{R} \varepsilon_{R} \kappa_{0}
$$

where $\kappa_{0}>0$ is an exogenous parameter, it then follows that the wage function (7) is linear in worker ability, $\varepsilon_{R}$. With these assumptions, we show in Appendix A.2.1 that the equilibrium tightness ratio implicitly solves:

$$
\left[\frac{1-\beta(1-\delta)}{q\left(\theta_{\varepsilon_{R}}\right)}+\beta \frac{\theta_{\varepsilon_{R}}}{1+\Psi}\right] \kappa_{0}=\beta \frac{\Psi}{1+\Psi}, \forall \varepsilon_{R}
$$

Hence, equilibrium tightness ratio is independent of productivities and capital prices, $\left\{\phi_{K}, \phi_{A}, f_{R}, f_{N R M}, f_{N R C}\right\}$. The same is true of tightness in NRM as well. The model yields a constant tightness ratio for each occu- 
pation in steady state, even as productivity (i.e. automation technology) changes. This makes the model consistent with the empirical patterns of the unemployment rate discussed in Section 2.

\subsection{Productivity cutoffs}

As indicated by (8), equilibrium tightness is also independent of worker ability. This is useful in establishing results regarding productivity cutoffs. In Appendix A.3 we show that the steady state values of unemployment can be expressed as:

$$
\begin{aligned}
V_{u, \varepsilon_{R}, \varepsilon_{N R M}} & \left.=\frac{\left(f_{R} P_{R} \varepsilon_{R}\right)^{1-\sigma}}{1-\beta}\right\urcorner_{R}\left(\varepsilon_{R}\right), \\
V_{u, \varepsilon_{N R M}, \varepsilon_{R}} & \left.=\frac{\left(f_{N R M} P_{N R M} \varepsilon_{N R M}\right)^{1-\sigma}}{1-\beta}\right\urcorner_{N R M}\left(\varepsilon_{N R M}\right),
\end{aligned}
$$

for all $\varepsilon_{R}, \varepsilon_{N R M}$. Here, $\urcorner_{R}\left(\varepsilon_{R}\right)$ and $\rceil_{N R M}\left(\varepsilon_{N R M}\right)$ are functions of exogenous parameters and occupation-andability specific tightness ratios:

$$
\begin{gathered}
\urcorner_{R}\left(\varepsilon_{R}\right)=\frac{\left(b \frac{1+\theta_{\varepsilon_{R}} \kappa_{0}}{1+\Psi}\right)^{1-\sigma}}{1-\sigma}+\left(\frac{1+\theta_{\varepsilon_{R}} \kappa_{0}}{1+\Psi}\right)^{-\sigma}\left[\left(1-T_{\varepsilon_{R}}\right)^{1-\sigma}-b^{1-\sigma}\right] \theta_{\varepsilon_{R}} \frac{\tau}{1-\tau} \kappa_{0}, \\
\neg_{N R M}\left(\varepsilon_{N R M}\right)=\frac{\left(b \frac{1+\theta_{\varepsilon_{N R M}} \kappa_{0}}{1+\Psi}\right)^{1-\sigma}}{1-\sigma}+\left(\frac{1+\theta_{\varepsilon_{N R M}} \kappa_{0}}{1+\Psi}\right)^{-\sigma}\left[\left(1-T_{\varepsilon_{N R M}}\right)^{1-\sigma}-b^{1-\sigma}\right] \theta_{\varepsilon_{N R M}} \frac{\tau}{1-\tau} \kappa_{0} .
\end{gathered}
$$

We have assumed that the unemployment insurance replacement rate, $b$, is constant across low-skill worker abilities. Equation (8) indicates that labor market tightness ratios are constant across abilities: $\theta_{\varepsilon_{R}}=$ $\theta_{R}, \forall \varepsilon_{R}$, and $\theta_{\varepsilon_{N R M}}=\theta_{N R M}, \forall \varepsilon_{N R M}$. If we assume that low-skill tax rates are independent of ability, $T_{\varepsilon_{R}}=$ $T_{R}, \forall \varepsilon_{R}$, and $T_{\mathcal{E}_{N R M}}=T_{N R M}, \forall \varepsilon_{N R M}$, this implies that $\left.\rceil_{R}\left(\varepsilon_{R}\right)=\right\rceil_{R}$ and $\left.\rceil_{N R M}\left(\varepsilon_{N R M}\right)=\right\rceil_{N R M}$ are constant across worker abilities.

This allows us to establish the following results. Recall that transfers to labor force non-participants is independent of ability; hence the value of non-participation is independent of ability. Therefore, we can solve for cutoff values $\varepsilon_{R}^{*}$ and $\varepsilon_{N R M}^{*}$ such that a worker with ability $\varepsilon=\left(\varepsilon_{R}, \varepsilon_{N R M}\right)$ below both cutoffs prefers labor force non-participation. These cutoffs are given by:

$$
\begin{aligned}
\varepsilon_{R}^{*} & =\frac{1}{f_{R} P_{R}}\left(\frac{b_{o}}{7_{R}}\right)^{\frac{1}{1-\sigma}}, \\
\varepsilon_{N R M}^{*} & =\frac{1}{f_{N R M} P_{N R M}}\left(\frac{b_{o}}{7_{N R M}}\right)^{\frac{1}{1-\sigma}} .
\end{aligned}
$$

Those who draw $\varepsilon$ above either cutoff (or both) choose to participate in the labor market. Which occupation the worker searches in is determined by the values of unemployment, $V_{u, \varepsilon_{R}}$ and $V_{u, \varepsilon_{N R M}}$. Specifically, 
for each $\varepsilon_{R}\left(>\varepsilon_{R}^{*}\right)$ there exists an $\hat{\varepsilon}_{N R M}$ such that for $\varepsilon_{N R M}<\hat{\varepsilon}_{N R M}$, the worker chooses unemployment in R, and for $\varepsilon_{N R M} \geq \hat{\varepsilon}_{N R M}$ the worker searches in NRM. This cutoff is the solution to:

$$
\left.\left.\frac{\left(f_{R} P_{R} \varepsilon_{R}\right)^{1-\sigma}}{1-\beta}\right\urcorner_{R}=\frac{\left(f_{N R M} P_{N R M} \varepsilon_{N R M}\right)^{1-\sigma}}{1-\beta}\right\urcorner_{N R M},
$$

implying a linear function of the form:

$$
\hat{\varepsilon}_{N R M}\left(\varepsilon_{R}\right)=\left(\frac{\rceil_{R}}{\rceil_{N R M}}\right)^{\frac{1}{1-\sigma}} \frac{f_{R} P_{R}}{f_{N R M} P_{N R M}} \varepsilon_{R} .
$$

This result is important from a computational perspective since it implies that the bounds of the various integrals in the model are linear. That together with tightness ratios being constant implies that we can solve for the equilibrium allocations and perform welfare calculations exploiting these closed form results, even though the model features curvature in utility, production, and frictions in the labor market.

\section{Quantitative Results}

In this section we calibrate the model economy and evaluate the impact of advancement in automation technology. We model this as a fall in the relative price of ICT capital, $\phi_{A}$ (or equivalently, an increase in the productivity in transforming final goods into ICT capital, $1 / \phi_{A}$ ). As a guide, we target pre-automation moments, feed in the observed change in the price of automation, and evaluate model performance by comparing 2017 predictions to observed US data.

\subsection{Calibration}

We begin this section by discussing the parametrization of the model. Table 5 lists the various parameters and their values.

Ability distribution As is common in the literature we assume the work ability distribution, $\Gamma\left(\varepsilon_{R}, \varepsilon_{N R M}\right)$, to be jointly log normal. Hence, there are five parameters to specify: two standard deviations, two means, and one correlation. Let $\sigma_{\varepsilon_{R}}\left(\mu_{\varepsilon_{R}}\right)$ be the standard deviation (mean) of the R ability, $\sigma_{N R M}\left(\mu_{N R M}\right)$ be the standard deviation (mean) of the NRM ability, and $\rho_{\varepsilon_{R}, \varepsilon_{N R M}}$ be the correlation between abilities. We note that the model is "scale free": the means of the distribution are irrelevant and we normalize them to unity. The correlation between the two abilities cannot be identified in the data. As such, we solve the model for various values of the correlation, $\rho_{\varepsilon_{R}, \varepsilon_{N R M}}$. Quantitatively, all of the results that we present here and in the policy experiments (Section 6) are virtually identical for different values of $\rho$. As such we proceed with a benchmark value of $\rho_{\varepsilon_{R}, \varepsilon_{N R M}}=0$ and present robustness results in Appendix A.5 
Table 5: Calibration

\begin{tabular}{ccl}
\hline \hline Parameter & Value & Target \\
\hline Ability Distribution & & \\
$\mu_{N R M}$ & 1 & Normalization \\
$\mu_{R}$ & 1 & \\
$\sigma_{N R M}$ & 0.9803 & Occupations allocations and variance of observed wages \\
$\sigma_{R}$ & 0.7436 & See text for details \\
$\rho_{R, N R M}$ & 0 & \\
Preferences & & \\
$\beta$ & 0.9957 & Monthly frequency; $r_{\text {annual }}=0.05$ \\
$\sigma$ & 1 & log utility \\
Labor Frisch Elasticity (NRC) & 0.5 & Chetty et al. (2013) \\
\hline Labor Market Frictions & & \\
$\delta$ & 0.02 & Monthly exit rate 1989 \\
elasticity of matches to $v$ & 0.5 & Pissarides and Petrongolo 2001$)$ \\
\hline Taxes and Transfers & & \\
$b_{N N R C}$ & 0.5 & Maximum allowed, US 1989 \\
$b_{o}$ & .0813 & Marginal worker indifferent between NLF and unemployment \\
$T_{N R M}$ & 0.137 & \\
$T_{R}$ & 0.137 & Average group tax rates \\
$T_{N R C}$ & 0.267 & \\
\hline
\end{tabular}

Depreciation Rates

$\begin{array}{lll}\delta_{K} & 0.06 \\ \delta_{A} & 0.19 & \text { Annual depreciation rates (see Eden and Gaggl (2018)) }\end{array}$

Prices of Capital

\begin{tabular}{ccl}
$\phi_{K}$ & 1 & \\
$\phi_{A}$ & 0.77 & Eden and Gaggl 2018) \\
$\phi_{A}^{2017}$ & 0.3244 & Fall in ICT prices 1989-2017 (see Eden and Gaggl (2018)) \\
\hline$\phi_{A}^{1989}$ &
\end{tabular}

Production Function: Shares

$\eta$

$\alpha$

$f_{R}$

$\tau$
.1099 Labor share, Routine Labor Share, ICT capital In-

0.8154 come share, 1989; and consistency restriction (see

0.3022

0.98

Equation 9)

\section{Production Function: Elasticities}

$\gamma$

$\varsigma_{2}$

$v$

$\varsigma_{1}$
0.31 Physical capital income share (see Eden and Gaggl (2018))

$0 \approx$ constant NRM income share

0.46

$-1.1$

Split of R workers between NLF and NRM and $\Delta \frac{X_{A}}{E M P_{R}}$ 
We identify the standard deviations, $\sigma_{\varepsilon_{R}}$ and $\sigma_{N R M}$, iteratively as follows. Given initial guesses for these two parameters, we find the ability cutoffs, $\varepsilon_{R}^{*}$ and $\varepsilon_{N R M}^{*}$, such that the model delivers the observed shares of low-skill workers (as identified in Section 2) in the routine and non-routine manual occupations in 1989 (with the share in labor force non-participation simply the residual).

Then, given the linearity of the wage and integral bounds in ability, $\varepsilon_{R}$, discussed in Section 4 , the $\log$ of the routine wage can be written as:

$$
\log \omega_{\varepsilon_{R}}=\log D+\log \left(\varepsilon_{R}\right),
$$

where $D$ denotes a costant that is identical for all $\varepsilon_{R}$. This implies that the log wage is distributed:

$$
\log \omega_{\varepsilon_{R}} \sim N\left(\mu_{\varepsilon_{R}}+\log D, \sigma_{R}\right)
$$

and thus, the variance of observed wages is given by:

$$
\operatorname{Var}\left(\log \omega_{R, \varepsilon_{R}} \mid \log \varepsilon_{R}>\log \varepsilon_{R}^{*}\right)=\operatorname{Var}\left(\log D+\log \varepsilon_{R} \mid \log \varepsilon_{R}>\log \varepsilon_{R}^{*}\right)
$$

Given that $D$ is a constant, this boils down to a variance in a truncated bivariate log normal:

$$
\operatorname{Var}\left(\log \varepsilon_{R} \mid \log \varepsilon_{R}>\log \varepsilon_{R}^{*}\right)
$$

with a similar expressions for the variance of observed $N R M$ wages. We iterate on the guesses of the standard deviations until the resulting truncated wages in the model match those in the data (the standard devaition of the log observed wages for Routine workers in the data in 1989 is 0.487 , while that for NRM equals 0.492).

Preferences The model is calibrated to a monthly frequency. We set $\beta=0.9957$, targeting an average annual risk free interest rate of $5 \%$. We set $\sigma=1$ so that preferences are logarithmic in consumption. Finally, recall that NRC/high-skill workers supply labor along the intensive margin. Their separable preferences over hours worked feature a Frisch labor supply elasticity of 0.5 (see Chetty et al. (2013)).

Frictional labor market parameters We set the exogenous monthly separation rate, $\delta$, equal to the 1989 rate of 0.02 ; this is the monthly transition rate from employment to unemployment in the CPS for workers whose last occupation was R or NRM. We assume a Cobb-Douglas matching function in each occupationability-specific market, with symmetric elasticity with respect to vacancies and unemployed, equal to 0.5 (e.g., Pissarides and Petrongolo (2001)). Without loss of generality, we assume an identical matching efficiency across all markets equal to 1 . We calibrate the vacancy cost parameter, $\kappa_{0}$ such that the resulting employment rate across the low-skill workers matches the evidence in Table 1 of 0.95 ; this implies a monthly job finding rate of 0.38 in all markets in the steady state. 
Government transfers There are two types of transfers in the model to low-skill workers: unemployment insurance, specified as a replacement rate of occupation-and-ability specific earnings, and transfers to labor force non-participants. We set the replacement rate for all workers types to 0.5 which is the maximum allowed value in the U.S. The transfer to non-participants is set internally to ensure that, when calibrated to match the 1989 shares of workers in R, NRM, and NLF, the marginal $\left(\varepsilon_{R}^{*}, \varepsilon_{N R M}^{*}\right)$ worker is indifferent between participating in the labor force and being unemployed 14

Taxes Government transfers are funded by taxes on profit and labor income. The labor tax schedule is progressive. We set the tax on unemployment and non-participant transfer income to zero. The tax rate on NRM and R labor income is set at $T_{R}=T_{N R M}=0.137$, approximately the average tax rate across the second to fourth quintiles of income, while for high-skill/NRC tax rate is set at $T_{N R C}=0.267$ which is the average federal tax rate for the fifth quintile of income. These tax rates are based on the estimates in the Congressional Budget Office distribution of household income in 2015.

At each calculation of a steady state equilibrium (before and after the decline in ICT price) we allow the profit tax rate, $T_{\pi}$, to adjust such that it balances the government budget constraint ${ }^{15}$

Depreciation rates We use the specific capital depreciation rates estimated by Eden and Gaggl (2018) and target an annual depreciation rate of $\delta_{A}=19 \%$ for ICT capital, and $\delta_{K}=6 \%$ on non-ICT, "physical" capital.

Relative prices of capital We use the same data to calibrate the initial relative price of ICT capital to consumption to equal $\phi_{A}^{1989}=0.77$. Our measure of advancement in automation technology is the fall in the relative price of ICT capital between 1989 and 2017. Based on the estimate in Eden and Gaggl (2018) we feed in a fall in the ICT price such that $\phi_{A}^{2017}=0.3244 \phi_{A}^{1989}{ }^{16}$ We set the relative price of physical capital to $\phi_{K}=1$.

Production and income share parameters We have assumed that aggregate production is Cobb-Douglas with respect to non-ICT capital, $K$; its share parameter is calibrated directly from the Eden and Gaggl

\footnotetext{
${ }^{14}$ To put this into context, the resulting value of steady state consumption of the least able worker is equal to 0.37 of the average R wage.

${ }^{15}$ Since investment is fully deducted in the model, this change has no effect on the economy. For all policy experiments in Section 6 we keep this tax rate constant and balance the budget with distortionary labor taxation on the NRC group.

${ }^{16}$ We note that the estimates in Eden and Gaggl (2018) end in 2013. We extrapolate both the price series and capital series until 2017 based on the median growth rate in these two series in the post Great Recession period. As a robustness check we note that during period they overlap the relative chained price index of private fixed investment in information processing equipment and software behave in an almost identical way to the Eden and Gaggl(2018) series. See https://fred.stlouisfed.org/series/B679RG3Q086SBEA.
} 
(2018) income share data to $\gamma=0.31$. As we discuss below, the NRM labor share of national income has not changed during our period of interest. As such, we set $\varsigma_{2}=0$ so that NRM input, $Y_{N R M}$, is also Cobb-Douglas in production.

The parameters $\eta, \alpha, f_{R}, f_{N R M}, \tau$ also determine various income shares. We normalize $f_{N R M}=1$. The data moments we match to identify the remaining four parameters are the shares of total labor income, Routine labor income, ICT capital income in GDP, and the fact that, when calibrated to 1989, pre-polarization values, the ratio of ability cutoffs must satisfy:

$$
\frac{\varepsilon_{N R M}^{*}}{\varepsilon_{R}^{*}}=\frac{P_{R} f_{R}}{P_{N R M} f_{N R M}}\left(\frac{\urcorner_{R}}{\rceil_{N R M}}\right)^{\frac{1}{1-\sigma}},
$$

in steady state equilibrium 17

Production function: elasticities The remaining two parameters cannot be identified from first moments in the data: $v$, which controls the elasticity of substitution between ICT capital and R labor services, and $\varsigma_{1}$, which controls the elasticity of substitution between $Y_{N R C}$ and the $\left(X_{A}, Y_{R}\right)$ composite.

To calibrate them, we feed in the observed ICT price fall and iterate over $v$ and $\varsigma_{1}$ such that we match two moments: (i) our Section 2 result of the 0.63/0.37 split between NLF and NRM in accounting for the fall in R employment propensity among the low-skilled, and (ii) the observed change in the ratio of ICT capital per employed R worker between 1989 and 2017 of 7.14 (i.e an increase of over 600\%). We find that the model matches these at values of $v=0.46$ and $\varsigma_{1}=-1$.1. Importantly, we do not target the overall total decline in routine employment when calibrating these parameters.

\subsection{Model Results}

In this subsection, we first present results on empirical moments that are not targeted in our model calibration and quantitative specification. We conclude with results on the model's welfare implications of advancement in automation technology, as captured by the fall in the relative price of ICT capital.

\subsubsection{Quantities and prices}

To evaluate the empirical relevance of the model, and the role of ICT price change as a driving force in automation, we consider several non-targeted moments, specifically: (i) the magnitude of the fall in $\mathrm{R}$ employment propensity among the low-skilled, (ii) the change in the labor share of national income and its

\footnotetext{
${ }^{17}$ This is akin to an RBC model where the disutility scaling parameter on labor supply is calibrated to match a given fraction of time spent in market activity in steady state.
} 
occupational composition, (iii) the behavior of the average NRM-to-R wage ratio, and (iv) the elasticity of ICT capital to its price. Table 6 compares these non-targeted moments in the model to their values in the data.

Likelihood of working in Routine With respect to the fall in the propensity of low-skill workers to work in Routine occupations, the model generates a fall of 7.85 percentage points (p.p.). As discussed in Section 2, Tables 1 - 2 suggest that unconditionally, the fall in the likelihood was 16 p.p. between 1989 and 2017. Thus, the model, when driven by the ICT price change, accounts for about half of this fall.

National Income Shares Between 1989 and 2017, the share of GDP accruing as labor income fell by 4.3 p.p. (see, for example, Karabarbounis and Neiman (2013)). The model, driven solely by the fall in the price of ICT capital, generates a fall of 2.44 p.p., slightly more than half of that observed in the data.

With respect to the composition of labor income, Eden and Gaggl (2018) show that changes were not evenly distributed across occupations. The routine occupational labor share of GDP fell dramatically by 9.51 p.p. between 1989 and 2017, more than twice that of aggregate labor's share. At the same time, the non-routine cognitive labor share rose by 4.17 p.p.; the share of GDP accruing to non-routine manual employment remained roughly constant, increasing by 0.67 p.p..

As in the data, the fall in the share of GDP accruing to routine occupational workers in the model (5.9 p.p.) is more than double the fall in aggregate labor (2.44 p.p.). Hence, the model accounts for roughly one-half to two-thirds of fall in aggregate and routine labor income share. Moreover, the model yields an increase in the share of income accruing to NRC labor of 3.5 p.p., very close to the change observed in the data. ${ }^{18}$

Relative wages One of the stylized facts associated with job polarization is the decline in the wage gap between middle-class routine jobs and low-wage non-routine manual jobs. Based on CPS outgoing rotation group data, the relative average hourly wage of R to NRM workers fell by about 10 percent during our period of interest 19

To determine the model's prediction for relative wages, we first note that the the model generates a fall of $7.4 \%$ in the wage per efficiency unit of routine labor, $\omega_{R}$, and an increase of $4.2 \%$ in the wage per efficiency units of NRM labor, $\omega_{N R M}$. These efficiency measures, of course, are not the empirically observed measures. As such, using the equilibrium efficiency wages, cutoffs, and employment rates, we construct the average

\footnotetext{
${ }^{18}$ Recall that the model is calibrated so that the NRM labor share of national income does not change.

${ }^{19}$ A similar fall, of approximately 12 percent, is observed in average hourly wages constructed from the March annual earning supplement of the CPS. We are grateful to Paul Gaggl for sharing this data with us.
} 
Table 6: The Effect of ICT Price Decline

\begin{tabular}{lcc}
\hline \hline & Data & Model \\
\hline $\begin{array}{l}\text { Employment } \\
\text { change in routine share (out of N-NRC) }\end{array}$ & -16 & -7.85 \\
& & \\
Income Shares (\% of GDP) & -4.30 & -2.39 \\
p.p. change: Total & -9.51 & -6.00 \\
p.p. change: Routine & 4.17 & 3.50 \\
p.p. change: Non-Routine Cognitive & 0.67 & 0.00 \\
p.p. change: Non-Routine Manual & & \\
Wages & & \\
$\%$ change in avg. wage gap: Routine/Non-Routine-Manual & -10.00 & -3.60 \\
GDP & & \\
$\%$ change in real per-capita GDP & 40 & 11 \\
Elasticity of ICT capital w.r.t. ICT price & 0.40 & 0.41 \\
\hline \hline
\end{tabular}

Notes: All changes are between 1989 and 2017; see Eden and Gaggl (2018) for income shares by occupation.

wages (conditional on working in the economy), $E\left(\omega_{R}\right)$, and $E\left(\omega_{N R M}\right)$. As Table 6 indicates, the average $\mathrm{R}$ to NRM wage ratio falls by $3.6 \%$, accounting for about a third of the observed change in the data.

Elasticity of ICT Capital to its Price Finally, we note also that the model matches the elasticity of ICT capital to its price, 0.40 as measured form the ICT capital stock and relative price data in Eden and Gaggl (2018). This, too, is not targeted in the model calibration.

\subsubsection{Output and Welfare}

Output What are the model's implications with respect to aggregate output? The fall in ICT price and the resulting equilibrium allocations increase GDP by 12\%. By way of comparison, between 1989 and 2017, output per capita has risen by about $40 \%$ in the data. Hence, the model implies that about a quarter of the change in observed output can be attributed to advancement in automation technology, as proxied by the drop in the relative price of ICT capital.

Measures of welfare What does automation and the increase in aggregate output mean for welfare? We show that, despite rich model heterogeneity, our assumptions allow us to derive simple closed form solu- 
tions that characterize welfare. We then use these welfare measures to outline the heterogeneous welfare implications of advances in automation technology.

Recall that the steady state value of being unemployed, with ability $\varepsilon_{R}$, and searching for employment in the R occupational market is given by:

$$
\left.V_{u, \varepsilon_{R}, \varepsilon_{N R M}}=\frac{\left(f_{R} P_{R} \varepsilon_{R}\right)^{1-\sigma}}{1-\beta}\right\rceil_{R}
$$

The steady state value of being employed is given by:

$$
V_{e, \varepsilon_{R}, \mathcal{E}_{N R M}}=\left[\frac{\left.\frac{\left(1-\beta\left(1-\mu\left(\theta_{\varepsilon_{R}}\right)\right)\right)}{1-\beta}\right\rceil_{R}-\frac{b^{1-\sigma}}{1-\sigma}}{\beta \mu\left(\theta_{\varepsilon, R}\right)}\right]\left(f_{R} P_{R} \varepsilon_{R}\right)^{1-\sigma} .
$$

Hence, the expected or average welfare of a labor force participant, with ability $\varepsilon_{R}$, who selects into the $\mathrm{R}$ occupation is a weighted average, with weights given by the unemployment and employment rates:

$$
V_{\varepsilon_{R}, \varepsilon_{N R M}}=U R_{\varepsilon_{R}} V_{u, \varepsilon_{R}, \varepsilon_{N R M}}+E R_{\varepsilon_{R}} V_{e, \varepsilon_{R}, \varepsilon_{N R M}}
$$

Substituting in from above, the consumption equivalent value of utility is naturally given by:

$$
C_{\varepsilon_{R}}=\left[U R_{\varepsilon_{R}} \frac{\urcorner_{R}}{1-\beta}+E R_{\varepsilon_{R}}\left[\frac{\left.\frac{\left(1-\beta\left(1-\mu\left(\theta_{\varepsilon_{R}}\right)\right)\right.}{1-\beta}\right\urcorner_{R}-\frac{b^{1-\sigma}}{1-\sigma}}{\beta \mu\left(\theta_{\varepsilon_{R}}\right)}\right]\right]^{\frac{1}{1-\sigma}} f_{R} P_{R} \varepsilon_{R} .
$$

A similar expression holds for labor force participants in the NRM occupation. This greatly simplifies the calculation of welfare and how they change across steady states.

We proceed as follows. Given the post-automation equilibrium cutoffs for $\varepsilon_{R}^{*, N E W}$ and $\varepsilon_{N R M}^{*, N E W}$, we simulate a billion low-skill individuals, drawing abilities from the calibrated joint log normal distribution. We then calculate the new steady state measures of NLF, R, and NRM as:

$$
\begin{gathered}
N L F^{N E W}=I\left(\varepsilon_{R} \leq \varepsilon_{R}^{*, N E W}\right) I\left(\varepsilon_{N R M} \leq \varepsilon_{N R M}^{*, N E W}\right) \\
N R M^{N E W}=I\left(\log \left(m^{\text {new }}\right)+\log \left(\varepsilon_{R}\right) \leq \log \left(\varepsilon_{2}\right)\right) I\left(\varepsilon_{N R M}^{*, N E W} \leq \varepsilon_{N R M}\right) \\
R^{N E W}=I\left(\log \left(m^{\text {new }}\right)+\log \left(\varepsilon_{R}\right)>\log \left(\varepsilon_{2}\right)\right) I\left(\varepsilon_{R}^{*, N E W} \leq \varepsilon_{R}\right)
\end{gathered}
$$

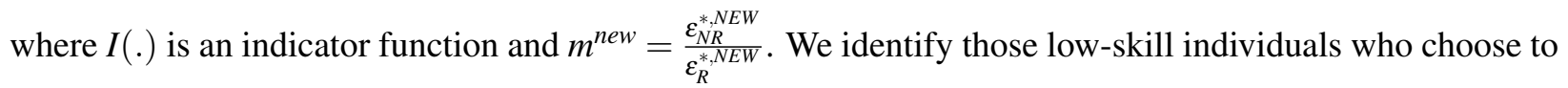
remain in their original occupation, and those who switch occupations or leave the labor force. In particular, following the ICT price change, the switchers are: (i) those used to be R and become NLF, (ii) those who used to be R and become NRM, and (iii) those who used to be NLF and become NRM. We calculate the percent change in consumption equivalent welfare due to automation for each group separately. 
Previously routine workers Consider those who choose the routine occupational market both pre- and post-automation. Their ratio of post- to pre-automation welfare, denoted by $\triangle R^{O L D} \rightarrow R^{N E W}$, is given by:

$$
\Delta R^{O L D} \rightarrow R^{N E W}=\frac{\left[U R_{\varepsilon_{R}} \frac{\urcorner_{R}}{1-\beta}+E R_{\varepsilon_{R}}\left[\frac{\left.\frac{\left(1-\beta\left(1-\mu\left(\theta_{\varepsilon_{R}}\right)\right)\right.}{1-\beta}\right\urcorner_{R}-\frac{b^{1-\sigma}}{1-\sigma}}{\beta \mu\left(\theta_{\varepsilon_{R}}\right)}\right]\right]^{\frac{1}{1-\sigma}} f_{R} P_{R}^{N E W} E\left(\varepsilon_{R}\right)^{R L D} \rightarrow R^{N E W}}{\left[U R_{\varepsilon_{R}} \frac{\rceil_{R}}{1-\beta}+E R_{\varepsilon_{R}}\left[\frac{\left.\frac{\left(1-\beta\left(1-\mu\left(\theta_{\varepsilon_{R}}\right)\right)\right.}{1-\beta}\right\urcorner_{R}-\frac{b^{1-\sigma}}{1-\sigma}}{\beta \mu\left(\theta_{\varepsilon_{R}}\right)}\right]\right]^{\frac{1}{1-\sigma}} f_{R} P_{R}^{O L D} E\left(\varepsilon_{R}\right)^{R^{O L D} \rightarrow R^{N E W}}}=\frac{P_{R}^{N E W}}{P_{R}^{O L D}},
$$

where $E\left(\varepsilon_{R}\right)^{R^{O L D} \rightarrow R^{N E W}}$ denotes the average ability of those who remain in $\mathrm{R}$. From equation $(8)$, recall that labor market tightness, employment/unemployment rates, and $\urcorner_{R}$ are invariant to changes in $\phi_{A}$. Hence, the change in welfare is exactly the change in prices that final goods producers pay for routine labor input; these prices are translated 1-to-1 to routine worker wages, their consumption, and (consumption equivalent) welfare. As indicated in the bottom panel of Column 1, Table 7, those who remain in R experience a $6.5 \%$ drop in welfare.

Welfare change derivations for those who switch occupations or labor force status are slightly more involved; details are provided in Appendix A.4. All results are displayed in the bottom panel of Column 1, Table 7

Some R workers have relatively high NRM abilities; post-automation, they switch into NRM (as opposed to remaining $\mathrm{R}$ or leaving the labor force). These workers see an average fall in welfare as well (though smaller than those who remain $\mathrm{R}$ ), amounting to $1 \%$ in consumption equivalent terms. Others who were previously R have relatively low NRM ability. After the fall in the return to R employment, they choose to exit the labor force. This group experiences an average welfare fall of $4 \%$.

All other workers Since NRM labor input is complementary to automation capital, the return to working (and searching) in that occupation rises. In the new steady state, all those who were previously in NRM choose to remain. Welfare increases by $5 \%$ for the average NRM stayer.

For most low-skill individuals who were out of the labor force, the fall in ICT capital price does not affect their participation choice. Since government transfers, $b_{o}$, are unchanged, their welfare is unchanged. However, those with sufficiently high NRM ability respond to the increase in the return to NRM labor, and switch to participating in the NRM occupational market. This group sees an average welfare increase of $3.2 \%$.

Finally, high-skill workers benefit the most from the decline in the price of automation technology, experiencing a consumption equivalent welfare increase of $22 \%$. This is not surprising since NRC labor input is 
a complement with ICT capital in production, and because they are the "capitalists" and hold all firm equity in the economy.

\section{Policy Experiments}

Given that we find an important quantitative role for automation, we use this new framework as a laboratory to consider a variety of government policies and their consequences for equilibrium allocations and welfare. We consider two sets of policies. First, we study the effects of a retraining program, targeted at improving the work ability (in a distributional sense) of the low-skilled. Second, we consider a broader set of redistribution policies that target transfers to the low-skilled. A number of these-such as reforms to the unemployment insurance system and the introduction of a universal basic income-have been discussed in the context of ameliorating inequality, and aiding those most negatively affected by automation.

Before proceeding, we note that it is possible to completely undo all of the equilibrium effects of the fall in $\phi_{A}$, through the introduction of a tax on purchases of ICT capital, $\tau_{A}$. Increasing $\tau_{A}$ to exactly offset the fall in $\phi_{A}$, leaving the effective ICT price unchanged, would return the economy to its pre-automation steady state values.

\subsection{Retraining program}

Our first policy experiment changes the ability distribution of low-skill workers in the face of automation. We consider a change in the marginal distribution of $\varepsilon_{N R M}$ ability (leaving the marginal distribution of $\varepsilon_{R}$ unchanged), capturing the idea of training low-skill workers to do non-routine manual work ${ }^{20}$ In this retraining policy, we target those who are out of the labor force (i.e. have ability below both cutoffs $\varepsilon_{R}^{*, N E W}$ and $\varepsilon_{N R M}^{*, N E W}$ ) in the 2017 , post-automation steady state ${ }^{21}$

Starting from the post-automation steady state (described in Column 1 of Table 7), we "offer" an additive increase in NRM ability to non-participants. For those with relatively high $\varepsilon_{N R M}$, the increase would improve their ability sufficiently to induce them to join the labor force and seek employment in the NRM occupation;

\footnotetext{
${ }^{20}$ The closest existing federal program would be the Trade Adjustment Assistance (TAA) program assisting workers in firms hurt by foreign trade. Among other benefits, this program pays for retraining. See for example the 2015 TAA benefits page: https://www.doleta.gov/tradeact/benefits/2015-amendment-benefits.cfm

${ }^{21}$ We view this as an empirically relevant exercise based on Card, Kluve and Weber (2018) who conduct a meta analysis of training programs, and find that training programs generally affect employment over longer horizons, with larger effect for the long-term unemployed (see, for example, Tables 3 and 9). These latter individuals are the most similar to the targeted individuals in our model analysis.
} 
Table 7: Policy Experiments

\begin{tabular}{|c|c|c|c|c|c|c|c|}
\hline & & $\begin{array}{c}\text { ICT } \\
\text { Change }\end{array}$ & Retraining & UI & UBI & $\begin{array}{c}\text { NLF } \\
\text { Benefits }\end{array}$ & Taxation \\
\hline \multicolumn{8}{|c|}{ Cutoffs } \\
\hline 1) & $\Delta \varepsilon_{R}^{*}$ & 6.70 & -0.22 & -3.95 & 10.77 & 26.37 & -9.66 \\
\hline 2) & $\Delta \varepsilon_{N R M}^{*}$ & -4.84 & 4.00 & -4.51 & 9.45 & 26.66 & -10.24 \\
\hline \multicolumn{8}{|c|}{ Labor states } \\
\hline 3) & $\Phi \mathrm{NLF}$ & 2.19 & -2.21 & -2.20 & 5.84 & 15.12 & -5.18 \\
\hline 4) & $\Phi \mathrm{R}$ & -3.82 & 0.27 & 1.57 & -4.69 & -11.52 & 3.81 \\
\hline 5) & $\Phi$ NRM & 1.64 & 1.94 & 0.64 & -1.15 & -3.60 & 1.37 \\
\hline 6) & Emp. Rate R & 0.95 & 0.95 & 0.945 & 0.946 & 0.95 & 0.95 \\
\hline 7) & Emp. Rate NRM & 0.95 & 0.95 & 0.945 & 0.946 & 0.95 & 0.95 \\
\hline 8) & $\Delta Y_{N R C}$ & 1.23 & 0.37 & 0.13 & -13.87 & -8.03 & -2.06 \\
\hline 9) & $\Delta Y_{R}$ & -3.72 & 0.60 & -0.11 & -5.03 & -12.37 & 3.13 \\
\hline 10) & $\Delta Y_{N R M}$ & 7.14 & 5.02 & -0.75 & -4.01 & -13.18 & 3.90 \\
\hline 11) & $\Delta \mathbf{G D P}$ & 11.98 & 1.02 & -0.06 & -10.42 & -10.04 & 0.29 \\
\hline 12) & $\Phi$ NRC labor tax & 0.00 & -1.51 & -0.50 & 35.19 & 25.00 & 9.98 \\
\hline \multicolumn{8}{|c|}{ Wages } \\
\hline 13) & $\Delta \omega_{R}$ & -6.70 & 0.22 & 0.14 & -7.22 & 3.42 & -4.19 \\
\hline 14) & $\Delta \omega_{N R M}$ & 4.84 & -4.00 & 0.70 & -5.90 & 3.14 & -3.61 \\
\hline 15) & $\Delta \omega_{N R C}$ & 23.24 & 0.83 & -0.30 & 7.50 & -3.79 & 4.45 \\
\hline 16) & $\Delta \omega_{N R C}:$ after tax & 23.24 & 0.85 & 0.11 & -12.80 & -10.64 & -2.82 \\
\hline \multicolumn{8}{|c|}{ Welfare: Consumption Equivalence } \\
\hline 17) & $\Delta: R^{\text {Old }} \rightarrow \Delta R^{\text {New }}$ & -6.48 & 1.23 & 1.75 & 6.23 & 3.48 & 10.13 \\
\hline 18) & $\Delta: R^{\text {Old }} \rightarrow \Delta N R M^{\text {New }}$ & -0.95 & NA & 2.56 & 11.69 & NA & 10.45 \\
\hline 19) & $\Delta: R^{\text {Old }} \rightarrow \Delta N L F^{N e w}$ & -4.01 & NA & NA & 26.25 & 16.69 & NA \\
\hline 20) & $\Delta: N R M^{\text {Old }} \rightarrow \Delta R^{\text {New }}$ & NA & -1.17 & NA & NA & 3.33 & NA \\
\hline 21) & $\Delta: N R M^{\text {Old }} \rightarrow \Delta N R M^{N e w}$ & 4.96 & -3.25 & 2.43 & 7.43 & 3.18 & 10.78 \\
\hline 22) & $\Delta: N R M^{\text {Old }} \rightarrow \Delta N L F^{N e w}$ & NA & -1.99 & NA & 27.12 & 16.64 & NA \\
\hline 23) & $\Delta: N L F^{\text {Old }} \rightarrow \Delta R^{\text {New }}$ & NA & 0.00 & 2.24 & NA & NA & 5.79 \\
\hline 24) & $\Delta: N L F^{\text {Old }} \rightarrow \Delta N R M^{N e w}$ & 3.17 & 9.23 & 2.51 & NA & NA & 6.09 \\
\hline 25) & $\Delta: N L F^{\text {Old }} \rightarrow \Delta N L F^{N e w}$ & 0.00 & 0.00 & 0.00 & 34.05 & 34.71 & 0.00 \\
\hline 26) & $\Delta: N R C^{\text {Old }} \rightarrow \Delta N R C^{\text {New }}$ & 22.64 & 1.98 & 0.07 & -21.89 & -22.99 & -4.98 \\
\hline
\end{tabular}

Notes: (i) $\Phi$ denotes percentage point change; (ii) $\Delta$ denotes percentage change; (iii) the reference point for the first column is the steady state beofre the ICT price decline; (iv) the reference point for columns 2-6 is the steady state after the ICT price decline. 
such workers would optimally select into the "retraining" treatment. Others with low $\varepsilon_{N R M}$ would not. We search for the NRM ability increase that returns low-skilled labor force participation to its 1989, preautomation value. We find that in order to return labor force participation back to its pre-automation level, an increase in $\varepsilon_{N R M}$ that equals about a quarter of the standard deviation of NRM ability is required. This induces about $10 \%$ of non-participants to select into treatment ${ }^{22}$

This experiment increases GDP by slightly more than $1 \%$, through two effects. First, since both labor force participation and NRM ability increase (for those who transition from outside the labor force into NRM occupations), there is a direct effect on labor input and, hence, output. Second, given the complementarity of NRM labor with ICT capital, it increases the return to investment, leading to an increase in the both types of capital stock, further contributing to output growth.

In terms of welfare, the main beneficiaries are naturally non-participants who, through retraining, move into the NRM occupation. They experience an increase in consumption equivalent welfare of just over $9 \%$. The second group to most benefit is the high-skilled, who experience a $2 \%$ increase in welfare. This is due to two channels. First, transfers to labor force non-participants are reduced, reducing their labor tax rate by about 1.5 p.p.. Second, the NRC wage increasing by almost 1 percent since they are complements in production to both NRM labor and automation capital.

With respect to the low-skill, those who were already working in NRM prior to the experiment see a fall in welfare. This is due to a displacement effect: the increase in the supply of NRM abilities leads to a fall in the efficiency price of their labor. This leads to an exit from the labor force of workers with NRM abilities that were close to the pre-retraining threshold ${ }^{23}$ Still others are induced to switch to the R occupation. The most negatively affected are those with sufficiently high $\varepsilon_{N R M}$ that remain in the occupation, and suffer from the fall in their wages, income, and welfare. Finally those who were working in R prior to retraining observe a small increase in welfare, since their labor is complementary to NRM labor.

Cost-benefit analysis Since the existing literature provides little guidance regarding the appropriate "production function" (and hence cost structure) of retraining programs, our analysis abstracts from the policy experiment's cost. Yet, it is instructive to provide a proxy in terms of cost-benefit analysis.

\footnotetext{
${ }^{22}$ Since the experiment results in an ability distribution that is no longer log normal, we cannot rely on closed form solutions of the bivariate log-normal distribution. Rather we rely on numerical simulation of one billion individuals and calculate the resulting equilibrium.

${ }^{23}$ Note that this experiment treated roughly ten percent of the NLF, which is about 3 percent of the population. Yet NLF went down by only 2.2 percentage points. Thus, there is an inflow into the NLF from the NRM due to the displacement effect of about 0.8 percentage points.
} 
This retraining induced an inflow from outside the labor force of approximately $10 \%$ (i.e. about $3 \%$ of the population), resulting in an increase of output of about $1 \%$. This means that as long as the various per participant cost channels of the program (i.e. labor, capital and potential increases in tax distortions) amount to less than about a third of per capita GDP, the retraining program has a positive return from an aggregate perspective.

\subsection{Redistributive transfers}

In this subsection we consider four redistributive policies transferring resources from high-wage workers (who, as shown in Section 5, significantly benefit from automation) to middle- and low-wage workers. The four policies are: (i) a reform to the unemployment insurance system (UI), (ii) the introduction of a universal basic income (UBI), (iii) increasing transfers to those outside of the labor force, and (iv) changes in the labor taxes levied on the low-skilled.

Given the general equilibrium emphasis of the model, each of these policies must be financed through increased government taxation. Our approach is to do so through increased labor income taxes of highskill (NRC) workers, those who have most benefited from automation. This is to be consistent with our interest in analyzing the effects of programs targeted toward those most adversely affected, in the model, by automation. This implies increasing the distortion on labor supply of high-skill workers.

\subsubsection{Unemployment Insurance Benefits}

We begin with a change to the UI, where workers receive an additional transfer while unemployed. We choose the size of this transfer so that, as in the retraining program discussed in Section 6.1, the low-skilled labor force participation rate returns to its 1989, pre-automation level. For comparability, we keep the "dollar value" of transfers per recipient fixed across the four redistributive experiments ${ }^{24}$

Specifically, we consider an increase in the generosity of UI benefits whereby an additional transfer, $U I>$ 0 , is provided to each unemployed worker. This is in addition to the existing unemployment benefit modelled as a replacement rate relative to the worker type's wage. As an example, consumption of an unemployed routine worker of type $\varepsilon_{R}$ becomes $C_{u, \varepsilon_{R}}=b \omega_{\varepsilon_{R}}+U I$. This additive term in the budget constraint (present also in the UBI analysis below) means that the linearity of the solution approach discussed in Section 4 is no longer applicable. As a result: (i) each labor market (segmented by $\varepsilon_{R}$ and $\varepsilon_{N R M}$ for R and NRM occupations, respectively) features a different tightness ratio, and (ii) the equilibrium cutoffs are no longer

\footnotetext{
${ }^{24}$ The qualitative effects across programs remains the same irrespective of the specific value we consider.
} 
linear functions of ability. Solving for the equilibrium requires additional numerical computation (e.g., numerical integration, spline approximation) 25

An Illustrative Simplified Model What is the effect of the increase in unemployment benefits on the economy? Before discussing the effects within the context of our GE model, we find it useful to discuss the effects of such a policy changes within a simplified search and matching model with CRRA preferences but (i) without heterogeneity in production, (ii) no taxes, and (iii) no curvature in production (i.e a constant productivity in production). Specifically, we consider an individual who prior to any UI policy change is indifferent between being unemployed or being outside of the labor force (i.e. the individual with $\varepsilon_{R}=\varepsilon_{R}^{*}$ ). This simplified model will help us emphasize the role of search frictions in driving the effect of the policy change on wages, unemployment and the labor participation decision. Figure 1 depicts the key outcomes of this simplified model.

Given concavity in preferences, a more generous UI system reduces the difference in utility between being employed and unemployed (see bottom left panel of Figure 1), a key object in the Nash bargaining problem. As a result, the bargained wage increases as the top left panel depicts 26 Since the worker's productivity does not change, this increase in the wage must result, via the free entry condition, in a fall in vacancy creation, and in the tightness ratio, which manifests itself in a fall in the job finding rate in the top right panel. Taken together, as the lower right panel depicts, the value of unemployment increase vs. the value of non-participation (which is not affected by change in the UI system). Hence, a more generous UI system leads to an increase in the value of participating in the labor force.

The Full GE model What are the effects in our full GE model? The third column in Table 7 reports the results of a more generous UI system within our full model economy.

First, as discussed above, the increase in UI benefits increases the value of being unemployed, while the value of being outside the labor force is not affected. This leads to an increase in the value of participating in the labor force as can be seen in the third row 27

While labor force participation increases, as in the simplified model above, the increase in UI benefits affects the wage and job finding rates. Hence, in the context of this UI experiment, quantitatively, a key channel through which these policies operate is via the bargaining problem and its impact on the wage

\footnotetext{
${ }^{25}$ Additional details are available upon request.

${ }^{26}$ The effect discussed here will also naturally be present in models with linear utility.

${ }^{27}$ Quantitatively, we look for the value of the UI transfer that leads the labor force participation of the low-skilled to return to its 1989 allocation. We find this value to be 25.7 percent of the average UI transfers in the economy. This value, which will also be used in the rest of the transfer experiments below, is equivalent to about 420 dollars per month in 2017.
} 
Figure 1: UI policy
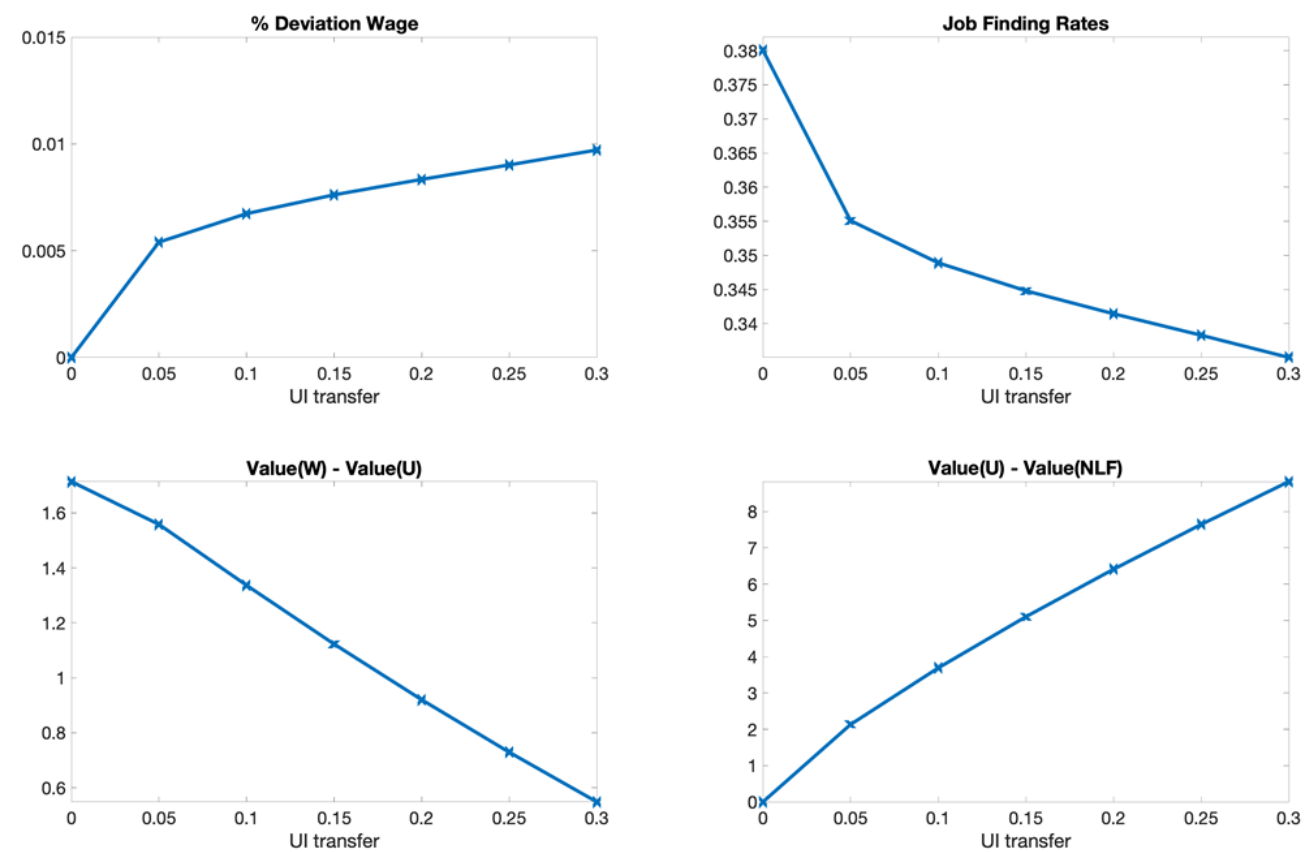

Notes: The x-axis depicts different UI transfers; a value of 0.3 matches the ratio of the UI transfer to the wage of the marginal Routine worker in our economy prior to the introduction of the program. Each line in the four different panels shows the response to changes in UI in a simple version of the model with no heterogeneity in production, no taxes, and no curvature in production. The $\%$ deviation in wages in the top-left panels are vis-a-vis the wage prior to the introduction of the increased UI benefits. 
Figure 2: UI policy: Effects on the relative wage and job finding rates
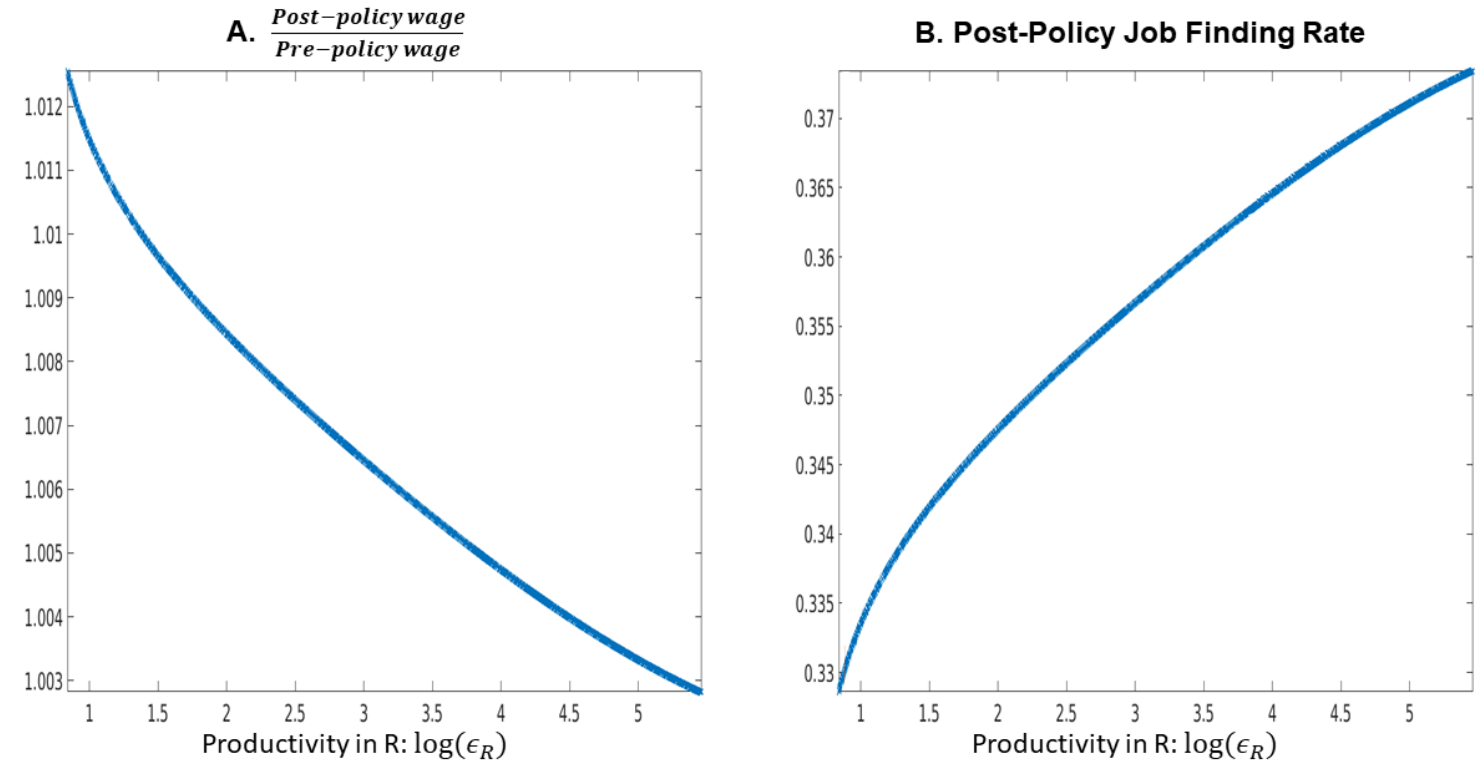

Notes: The x-axis for both panels is $\log \left(\varepsilon_{R}\right)$. The support includes productivity to the right of the $\varepsilon_{R}^{*}$ cutoff

and vacancies posting by firms. To discipline our analysis we require the model to match the elasticity of unemployment duration to unemployment benefits (see Appendix A.6 for a discussion).

Figure 2 depicts the heterogeneous equilibrium effects on the wage and on the job finding rate of the more generous UI policy in our full GE model. The left panel displays the ratio of the new post-policy wage to the pre-policy (and post-automation) wage, for each routine ability level, $\varepsilon_{R}$. As discussed above in the simplified version of the economy, the increase in the UI transfer leads to an increase in the wage. Figure 2 suggests that the wage increases at each ability (ranging from approximately $0.3 \%$ to $1.2 \%$ ), though proportionately more at low ability levels as the additional transfer is a larger fraction of income and has a bigger effect on the bargaining problem. The wage increase reduces the job finding rate as shown in the right panel of Figure 2. For reference, the job finding rate was 0.38 at each ability level prior to the policy change. This fall in the job finding rate manifests itself as an increase in the unemployment rate, more so at lower ability levels.

Overall, as row 11 in Table 7 reports, the introduction of the UI policy leaves aggregate output essentially unchanged (falling by less than one-tenth of one percent), despite the increase in labor force participation. This is due to the fact that the unemployment rate also increases. That is, the increased generosity of the UI program implies that conditional on participating in the labor force there is a fall in the employment rate, 
which can be seen in the sixth and seventh row in Table 7. Hence, the change in the job finding rate due to the increased UI essentially cancels the increase in labor force participation, leading overall to a minuscule fall in the supply of R and NRM labor input, which is observed in the ninth and tenth rows. The reduction in the labor tax levied on the NRC workers (see the 12th row and below for a discussion) increases slightly their labor input (see the eighth row) and overall leads to output essentially remaining the same.

In terms of welfare, the UI policy has relatively modest effects, at least relative to the other experiments reported in Table 7. With respect to the low-skilled, the increase in the UI benefits, and its equilibrium effects on wages, dominate the increase in the unemployment rate; consumption equivalent welfare rises by about $2 \%$, with small differences across groups as can be seen in rows 17-25.

Interestingly, as row 26 reports, high-skill workers see essentially no change in their welfare, rising by about $0.1 \%$. While transfers to the unemployed increase, this is offset by reduced transfers to those outside the labor force. As a result, the after-tax wages of the high-skilled are almost unchanged.

To summarize, the increase in UI generosity is found to be welfare improving for all groups, though somewhat modest at the level required to match our labor force participation target ${ }^{28}$

\subsubsection{Universal Basic Income}

Our next experiment introduces a universal basic income transfer program. We model the UBI as an identical lump sum transfer, $U B I>0$, to each individual, irrespective of her skill or labor force status. To make the policy experiments comparable, we keep the transfer per person the same as in the UI policy case. As an example, the budget constraint for a routine worker of type $\varepsilon_{R}$ becomes $C_{e, \varepsilon_{R}}=\omega_{\varepsilon_{R}}\left(1-T_{R}\right)+U B I 29$

As the fourth column of Table 7 reports, the UBI program reduces GDP by over 10 percent. This is due to a fall in the labor force participation and employment of the low-skilled workers, and a fall in the labor input of the high-skilled workers. What are the reasons for such a difference vs. the UI case analysed previosuly? As we discuss below, because of its budgetary implications, the UBI program requires a steep increase in the labor tax rate the NRC group faces, leading to a fall in the supply of their hours worked, which alters the return to labor force participation for the low-skilled workers in the economy.

\footnotetext{
${ }^{28}$ Given the model's inherent non-linearity, it is an open question as to how welfare would change for larger UI policy interventions.

${ }^{29}$ As with the case of the UI policy, having an additive term in workers' budget constraints means that the linearity of the solution approach discussed in Section 4 is no longer applicable. We follow the same solution approach in Section 6.2.1 Moreover, this policy experiments adds a new expenditure term to the government budget constraint, eq. 6
} 
An Illustrative Simplified Model Again, using a simplified model is helpful in disentangling the channels through which the policy affects the economy. Figure 3 depicts the results from two simplified models.

First, consider the simplified model we have used in the discussion of the UI policy above, referred to as Equilibrium/DMP in Figure 3. Under the UBI policy, individuals receive a transfer unconditional on their employment state. This induces a change in the value of employment, non-participation, as well as the value of being unemployed. Due to concavity of preferences, the difference between being unemployed and employed falls, as in the UI case (bottom left panel). This strengthens the worker's bargaining position and leads to an increase in the bargained wage (upper left panel) and to a fall in the job finding rate (upper right panel). Overall, this increase in the value of unemployment, increases the value of participation. However, unlike the UI case, with UBI, the value of non-participation increases at the same time. Which force dominates? As depicted in the bottom right panel of Figure 3, in this Equilibrium/DMP case, the value of unemployment minus the value of non-participation increases, implying that the DMP forces would be pushing to an increase in participation.

However, the UBI transfers to all individuals in the economy naturally need to be financed. As we show below, in our full model, this financing requirement induces a massive increase in the distortionary taxation NRC workers face, leading to a fall in their labor input. Because the NRC workers are complements to the $\mathrm{R}$ and NRM workers, the significant fall in the NRC labor input leads overall to a fall in the wages of $\mathrm{R}$ and NRM workers. To mimic this fall in productivity (which we show below in our full model economy) in this simplified version, we repeat the Equilibrium/DMP exercise with a single change, where we feed in a fall in the worker's productivity that matches the percentage fall in the worker's productivity as in our full GE model economy (of about 6 percent). This is depicted as the "Equilibrium/DMP + Prod Fall" in Figure 3. In this case, the fall in the wage is big enough to overturn the results discussed above, and the value of non-participation increases vis-a-vis the value of being unemployed (and participating). This discussion highlights the importance of analysing the effects of UBI within a GE model with government budget constraints. Without considering the budgetary needs to finance the UBI program, its introduction would have led to an increase in labor force participation.

The Full GE model The overall effects in our full model economy are presented in the fourth column in Table 7. The above discussion regarding the relative values of being unemployed or outside the labor force is reflected in the ability cutoffs for participation in the labor force increasing, as the first two rows in Table 7 report. As discussed above, all else equal, even though workers receive the UBI both when they are unemployed and employed, the curvature in the utility implies that, conditional on labor force participation, 
Figure 3: UBI policy
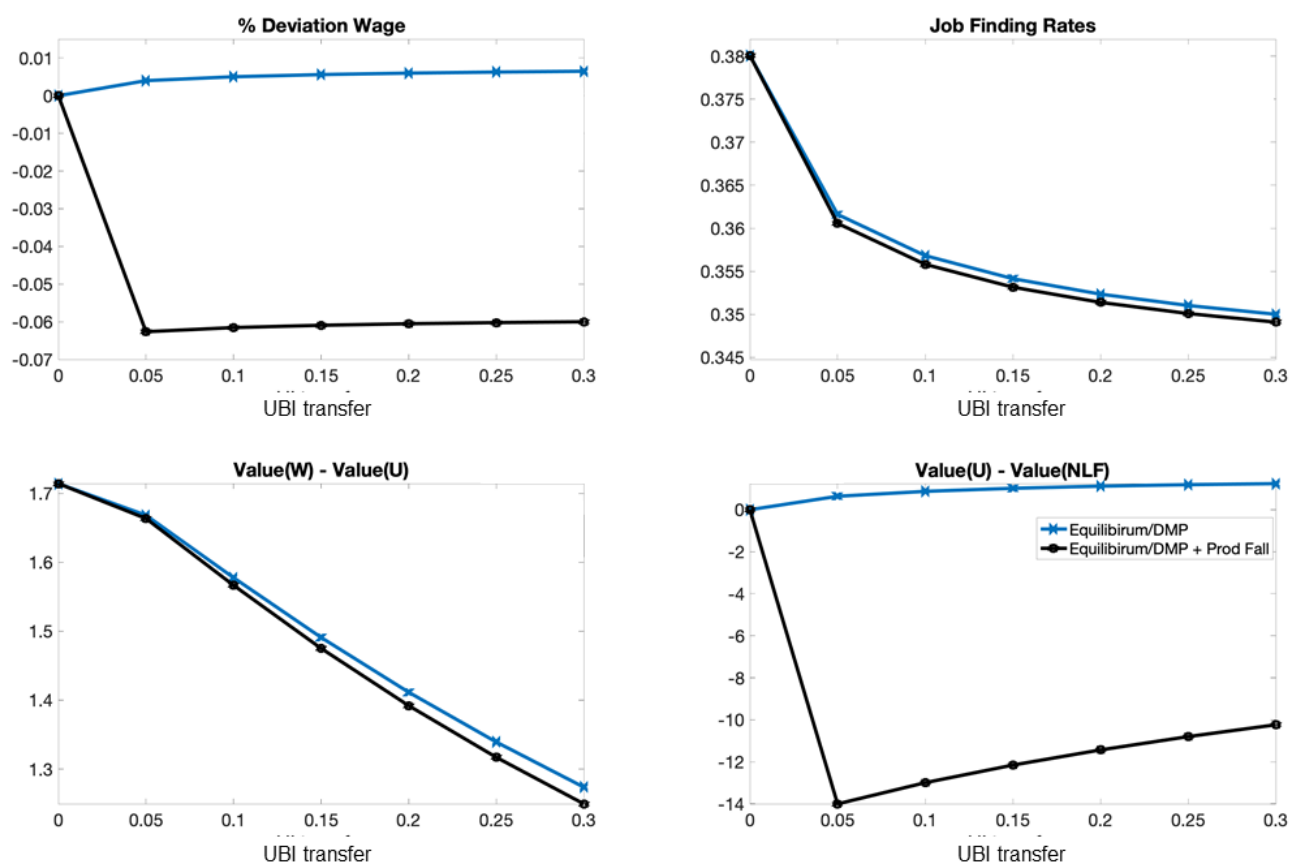

Notes: The x-axis depicts different UBI transfers; a value of 0.3 matches the ratio of the UBI transfer to the wage of the marginal Routine worker in our economy prior to the introduction of the program. The Equilibrium/DMP line shows the response to changes in UBI in a simple version of the model with no heterogeneity in production, no taxes, and no curvature in production. The Equilibrium/DMP+Prod Fall is similar to the Equilibrium/DMP model, but where we feed a fall in the worker's productivity that matches the percentage fall in the worker's productivity due to the fall in NRC labor input in our full model.

the increase in the value of unemployment versus employment improves the worker's outside option in the Nash bargaining: wages increase, job creation falls, and unemployment rises (as in the previous UI experiment).

However, as rows 13-14 in Table 7 indicate, there is no increase in $\omega_{R}$ and $\omega_{N R M}$ in equilibrium. As discussed above, this is because the primary effect of the UBI is its fiscal burden. Financing this transfer to all individuals requires a stark increase in taxation levied on the NRC workers; it has to increase by 35 percentage points in order to fund the UBI payment (see row 12). This leads to an obvious fall in NRC labor input of about $13 \%$ as the eighth row report. Since NRC labor input is complementary to routine and nonroutine manual work, the large fall in high-skill labor supply reduces the marginal product of low-skilled labor. As in the simplified model discussion above, this reduces the value of labor force participation being 
Figure 4: UBI policy: Effects on the relative wage and job finding rates
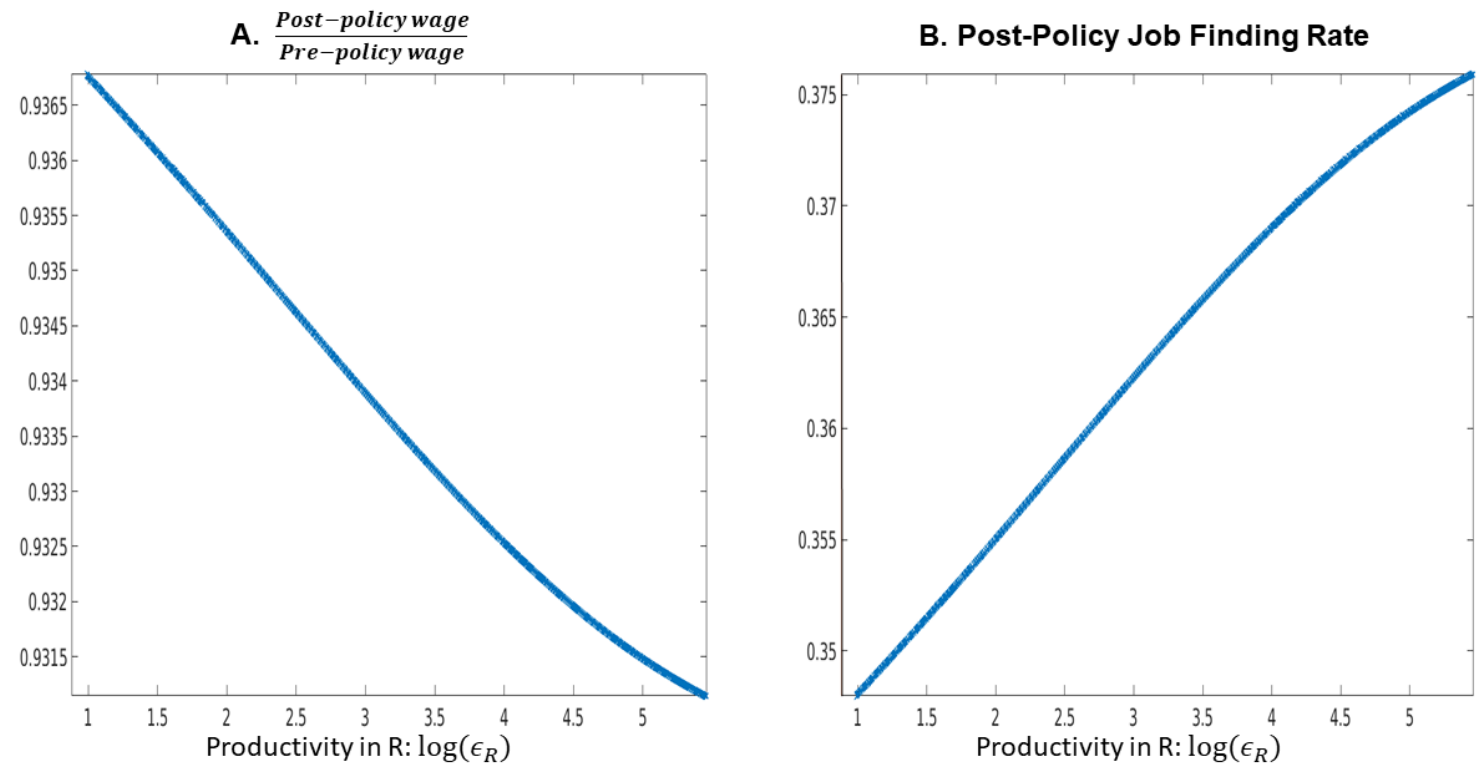

Notes: The x-axis for both figures is $\log \left(\varepsilon_{R}\right)$. The support includes productivity to the right of the $\varepsilon_{R}^{*}$ cutoff

reflected in the increase in NLF as reported in the third row.

Figure 4 depict the effects on the wage and the job finding rate of a more generous UBI system within our full model economy. Consider first the left panel, which depicts the ratio of the new equilibrium wage to the pre-UBI wage, for each routine ability level, $\varepsilon_{R}$. Post-UBI, the wage falls for each ability, by about 6 to 7 percent though less so for the lower ability. First, the fall in the productivity of $\mathrm{R}$ workers due to the fall in the supply of NRC workers is common to all R workers (and similarly for the NRM workers). However, for these lower ability (and low skilled) workers, the UBI transfer amounts to a bigger fraction of income and thus strengths their bargaining position by more vis-vis the higher ability low-skilled workers.

This fall in productivity of $\mathrm{R}$ workers lowers the job finding rate as shown in the right panel of Figure 4 where we remind the reader that, prior to the introduction of the UBI policy change the job finding rate was 0.38 for each ability. Since wages fall by more for higher ability low-skilled workers, their job finding rates fall by less relatively to lower ability low-skilled workers. Overall, naturally, this fall in the job finding rates for $\mathrm{R}$ workers manifests itself as an increase in the unemployment rate, more so at the lower ability levels, as being reflected in the sixth and seventh rows of Table 7.

Overall then, the introduction of the UBI program leads to an increase in the value of non-participation, drawing workers out of the labor force. This effect is several times larger than the effect of automation itself. 
In terms of welfare, the UBI program delivers significant heterogeneity in effects. Although high-skill workers receive a UBI transfer, this is more than offset by the fall in after-tax labor income and equity income (as the economy's firm owners). As the last row reports, they experience an approximate $22 \%$ consumption equivalent welfare reduction, similar in absolute magnitude to their welfare gain due to automation!

By contrast, the low-skilled experience significant welfare gains. These gains are present especially for those who choose to remain in, or transition toward, labor force non-participation. However, even the lowskilled who remain working enjoy an increase in their welfare (although their wages fall) from the mere fact that the UBI transfer is big enough vis-a-vis their wage and thus it accounts for a significant part of their income.

\subsubsection{Transfers to non-participation}

The next policy experiment is one in which transfers to labor force non-participants is increased. As before, the size of the increase, per each non-participant, is the same in dollar terms to those previously considered.

Not surprisingly, this program leads to a decrease in labor force participation as shown in the fifth column in Table 77, non-participation rises by 15 percentage points (see the third row). To finance the program, the distortionary tax rate on high-skill labor increases by 25 p.p (see the 12th row), leading to a fall in NRC labor input (see the eighth row). As a result of the decrease in both low- and high-skilled labor, aggregate output falls by $10 \%$.

As with the UBI policy, the high-skilled see a large decrease in after-tax labor income and equity income. As the last row reports, their welfare falls by $23 \%$. For the low-skilled, the greatest beneficiaries are those who choose labor force non-participation. These individuals enjoy a rise in welfare as in the UBI case. For those who remain in the labor force, the exit from participation of the lower ability low-skilled workers increases their welfare modestly, via the equilibrium effect on their wages; overall this group's welfare increases by about half of their increase in the UBI case.

\subsubsection{Progressivity of taxation}

The policy experiments of Sections 6.2.2 and 6.2.3 indicate much room for redistribution; but such transfer programs come at a dramatic cost, in terms of aggregate output and distortionary welfare losses for high-skill workers. Here, in our last experiment, we explore an alternative way to redistribute resources that involves smaller output and welfare losses for the high-skilled.

Specifically, we consider a more progressive tax system, where we reduce the labor tax rate, $T_{N R M}=T_{R}$, that low-skill workers pay. To keep results comparable to those above, we reduce the average tax receipt 
from each worker by the same dollar value as the per recipient transfer of Sections 6.2.1 through 6.2.3. To accomplish this, the tax rate falls to essentially zero and for simplicity, we set $T_{N R M}=T_{R}=0$. Maintaining government budget balance requires an increase in the labor tax rate levied on high-skill workers.

The sixth and final column in Table 7 reports the effect of this policy. First, in equilibrium, as the 12th row reports, this policy requires an increase in the tax rate levied on the high skilled of 10 p.p., which is markedly smaller than those of Sections 6.2.2 and 6.2.3.

The elimination of income taxation on low-skill workers naturally increases their value of participation, leading to approximately a five percentage point increase in their labor force participation. In contrast, the tax increase on the high-skilled leads to a fall in their labor supply (see the eighth row), but of lower magnitude than the cases of the UBI and transfers to the NLF policies. These offsetting changes in employment and labor supply are reflected in the pre-tax wage rates earned in R, NRM, and NRC occupations. These offsetting changes also imply that there is essentially no impact on aggregate output.

Overall, the increase in the supply of low-skilled and the decrease in the supply of the high-skilled leads to a pre-tax fall in the low-skilled wages (see rows 13 and 14). However, the after tax wages of the low-skilled increase by about 10 percent.

This increase in after tax wages implies that, in terms of welfare, this policy experiment delivers similar welfare gains to the low-skilled that participate in the labor market as the UBI experiment. However, as opposed to gains being reaped disproportionately by those out of the labor force (who do not see an increase in their welfare in this tax reform case), increasing the progressivity of taxation favors those who remain in, and select into, labor force participation. Hence, this is a successful policy in improving the welfare of those low-skilled workers who participate in the labor market as well as increasing labor force participation.

Finally, we note that this experiment also results in much smaller welfare losses (on the order of 5\%) for the high-skilled relative to the of UBI or increasing transfers to non-participants policies.

\subsubsection{Summary and program comparison}

To summarize, we use the model to evaluate macroeconomic and distributional impacts of various public policy proposals. A retraining policy, aimed at restoring labor force participation through improving the ability of workers in NRM occupations, is successful at doing so at relatively low back-of-the-envelope cost. It also increases aggregate income. However, it crowds out other low-skill workers, and it is unclear whether such a retraining program exists in practice at such a large scale.

A policy that increases the generosity of UI benefits is also able to restore labor force participation rates to pre-automation levels. It raises unemployment, has little impact on aggregate income, and is mildly welfare 
improving to all. For the majority of low-skilled workers, the increase in welfare is about half of the welfare loss they experienced due to the fall in the ICT price.

By contrast, the introduction of a UBI or an increase in the generosity of transfers to labor force nonparticipants reduce labor force participation, labor supply, and aggregate income. Moreover, while increasing welfare to the low-skilled (in the UBI case this welfare increase is bigger in absolute value than the welfare loss due to automation), they impose large welfare costs to the high-skilled.

Finally, increasing the progressivity of the tax system has strong redistributive effects, raises labor force participation, has little impact on aggregate income, and imposes relatively small welfare losses to the highskilled. For those low-skilled that remain in the labor force, the increase in their welfare is bigger than the welfare loss they experienced due to the fall in ICT prices.

\section{Conclusions}

We consider the dramatic change in the occupational composition of employment—specifically, the disappearance of employment in middle-wage routine occupations-observed over the past 35 years. Empirically, we find that for individuals who were most likely to work in routine occupations, the decline in such job opportunities was offset by increased likelihood of both labor force non-participation and employment in low-wage non-routine manual occupations, with the former outcome exceeding the latter approximately 2-to-1.

We develop a heterogeneous agent macroeconomic model with investment in automation capital, labor force participation and occupational choice, and government policy. When subjected to the empirically observed change in the relative price of ICT capital, the model accounts for about half of the decline in routine employment, the fall in total labor's share of national income, and the divergent changes in occupational labor income.

We use this model to study the aggregate and distributional impact of various public policy proposals; our experiments are redistributive in nature as government budget balance is maintained through increased taxation of the high-skilled. While a number of programs-including retraining, and unemployment insurance and labor taxation reforms - are promising, proposals such as universal basic income are highly costly. We view our framework as useful for the evaluation of many other policies that can differ in implementation, intensity, and redistributive focus in the face of automation. 


\section{References}

Abel, Andrew. 2007. “Optimal Capital Income Taxation.” NBER Working paper 13354.

Acemoglu, Daron, and David Autor. 2011. "Skills, tasks and technologies: Implications for employment and earnings." In Handbook of labor economics. Vol. 4, 1043-1171. Elsevier.

Acemoglu, Daron, and Pascual Restrepo. 2019. "Robots and Jobs: Evidence from US Labor Markets." Journal of Political Economy.

Altonji, Joseph G, Prashant Bharadwaj, and Fabian Lange. 2012. "Changes in the characteristics of American youth: Implications for adult outcomes.” Journal of Labor Economics, 30(4): 783-828.

Atalay, Enghin, Phai Phongthiengtham, Sebastian Sotelo, and Daniel Tannenbaum. 2018. "New technologies and the labor market." Journal of Monetary Economics, 97: 48-67.

Autor, David H., and David Dorn. 2013. "The growth of low-skill service jobs and the polarization of the US labor market." American Economic Review, 103(5): 1553-97.

Autor, David H, Frank Levy, and Richard J Murnane. 2003. "The skill content of recent technological change: An empirical exploration." The Quarterly journal of economics, 118(4): 1279-1333.

Autor, David H., Lawrence F. Katz, and Melissa S. Kearney. 2006. "The Polarization of the U.S. Labor Market." American Economic Review, 96(2): 189-194.

Beaudry, Paul, David A. Green, and Benjamin M. Sand. 2016. "The Great Reversal in the Demand for Skill and Cognitive Tasks.” Journal of Labor Economics, 34(S1): 199-247.

Card, David, Jochen Kluve, and Andrea Weber. 2018. "What Works? A Meta Analysis of Recent Active Labor Market Program Evaluations.” Journal of the European Economic Association, 16(3): 894-931.

Chetty, Raj. 2008. "Moral Hazard versus Liquidity and Optimal Unemployment Insurance." Journal of Political Economy, 116(2): 173-234.

Chetty, Raj, Adam Guren, Day Manoli, and Andrea Weber. 2013. "Does Indivisible Labor Explain the Difference between Micro and Macro Elasticities? A Meta-Analysis of Extensive Margin Elasticities." NBER Macroeconomics Annual, 27: 1-56. 
Cortes, Guido Matias, Nir Jaimovich, and Henry E. Siu. 2017. "Disappearing routine jobs: Who, how, and why?" Journal of Monetary Economic, 91: 69-87.

Cortes, Guido Matias, Nir Jaimovich, and Henry E. Siu. 2018. "The End of Men and Rise of Women in the High-Skilled Labor Market."

Cortes, Matias. 2016. "Where Have the Middle-Wage Workers Gone? A Study of Polarization using Panel Data." Journal of Labor Economics, 34(1): 63-105.

Diamond, Peter A. 1982. "Wage determination and efficiency in search equilibrium.” The Review of Economic Studies, 49(2): 217-227.

Eden, Maya, and Paul Gaggl. 2018. "On the Welfare Implications of Automation." Review of Economic and Dynamics, 29: 15-43.

Gaggl, Paul, and Greg C. Wright. 2017. "A Short-Run View of What Computers Do: Evidence from a U.K. Tax Incentive A Short-Run View of What Computers Do: Evidence from a U.K. Tax Incentive." American Economic Journal: Applied Economics, 9(3): 262-294.

Goos, Maarten, Alan Manning, and Anna Salomons. 2009. "Job Polarization in Europe." American Economic Review, 99(2): 58-63.

Goos, Maarten, and Alan Manning. 2007. "Lousy and Lovely Jobs: The Rising Polarization of Work in Britain." The Review of Economics and Statistics, 89(1): 118-133.

Jaimovich, Nir, and Henry E Siu. 2012. "The trend is the cycle: Job polarization and jobless recoveries." National Bureau of Economic Research.

Karabarbounis, Loukas, and Brent Neiman. 2013. "The global decline of the labor share.” The Quarterly journal of economics, 129(1): 61-103.

Meyer, Bruce D. 1990. “Unemployment Insurance and Unemployment Spells.” Econometrica, 58(4): 757782.

Michaels, Guy, Ashwini Natraj, and John Van Reenen. 2014. "Has ICT polarized skill demand? Evidence from eleven countries over 25 years." Review of Economics and Statistics, 96(1): 60-77.

Mortensen, Dale T. 1982. “The matching process as a noncooperative bargaining game.” In The economics of information and uncertainty. 233-258. University of Chicago Press. 
Pissarides, Christopher A. 1985. "Short-Run Equilibrium Dynamics of Unemployment, Vacancies, and Real Wages.” The American Economic Review, 75(4): 676-690.

Pissarides, Christopher A., and Barbara Petrongolo. 2001. "Looking into the Black Box: A Survey of the Matching Function.” Journal of Economic Literature, 39(2): 390-431.

Tuzel, Selale, and Miao Ben Zhang. 2019. "Economic Stimulus at the Expense of Routine- Task Jobs." Working Paper.

vom Lehn, Christian. 2019. "Labor market polarization, the decline of routine work, and technological change: A quantitative analysis." Journal of Monetary Economics.

Yedid-Levi, Yaniv. 2016. "Why does employment in all major sectors move together over the business cycle?" Review of Economic Dynamics, 22: 131-156. 


\section{A. Appendix}

\section{A.1. Data}

\section{A.1.1. CPS Data construction}

We adopt the occupational classification system used in Jaimovich and Siu (2012) that affords ease of data access and replication. The classification is based on the categorization of occupations in the 2000 Standard Occupational Classification system. Non-routine cognitive workers are those employed in "management, business, and financial operations occupations" and "professional and related occupations". Routine cognitive workers are those in "sales and related occupations" and "office and administrative support occupations". Routine manual occupations are "production occupations", "transportation and material moving occupations", "construction and extraction occupations", and "installation, maintenance, and repair occupations". Non-routine manual occupations are "service occupations". Detailed information on 3-digit occupational codes are available from the authors upon request.

\section{A.1.2. Classification errors}

Our ML approach classifies each person (at each point in time) into one of the four "likely" occupational groups (NRC, RC, NRM, and RM). However we present our main results aggregating to two workers types - NRC and non-NRC, hence Tables A1 and A2 show the confusion matrices for those two categories, separately for men and women respectively. In each matrix we add the precision (share of correctly classified objects within a predicted category) and recall (share of observed that were picked up by the prediction within a category) values. 
Table A1: Confusion Matrix - Men Classified

\begin{tabular}{c|cccc} 
& & NRC & non-NRC & Precision \\
True & NRC & 506,002 & 294,252 & $\mathbf{6 3 . 2 3 \%}$ \\
& non-NRC & 242,256 & $1,213,131$ & $\mathbf{8 3 . 3 5 \%}$ \\
Recall & $\mathbf{6 7 . 6 2 \%}$ & $\mathbf{8 0 . 4 8 \%}$ &
\end{tabular}

Table A2: Confusion Matrix - Women

$$
\text { Classified }
$$

\begin{tabular}{c|cccc}
\cline { 3 - 5 } True & & NRC & non-NRC & Precision \\
NRC & 342,362 & 150,507 & $\mathbf{6 9 . 4 6 \%}$ \\
non-NRC & 241,376 & $1,167,622$ & $\mathbf{8 2 . 8 7 \%}$ \\
Recall & $\mathbf{5 8 . 6 5 \%}$ & $\mathbf{8 8 . 5 8 \%}$ &
\end{tabular}




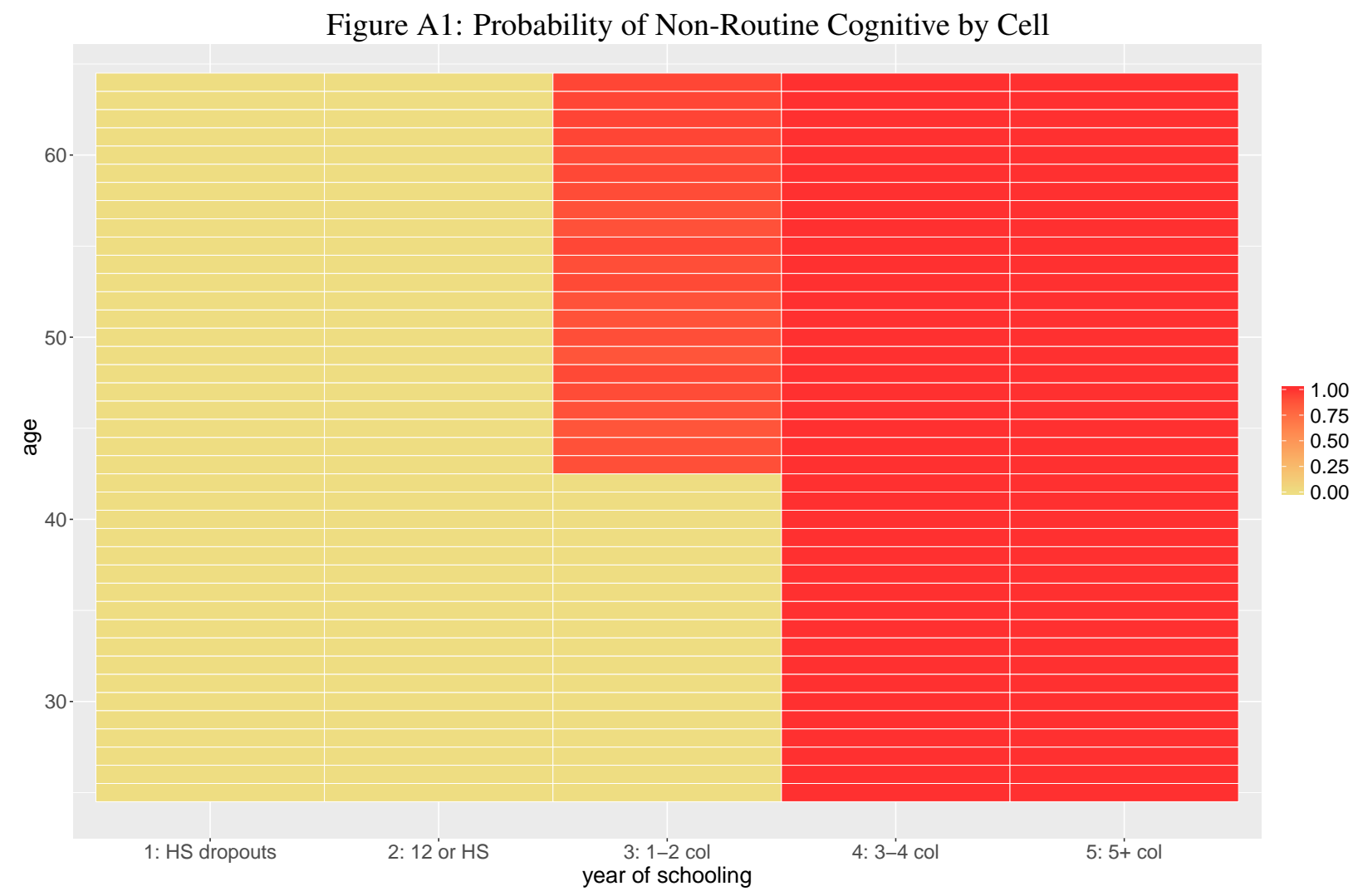

Notes: The probability of men in a specific education-age cell to be classified as non-NRC by the random forest algorithm. 


\section{A.1.3. Recovering true series from series with errors}

The classification errors discussed in A.1.2 imply that we do not have "clean" series for the dynamics of NRC and non-NRC type persons. However, we show now that while we cannot recover perfectly correct the classification a the individual level, it is possible to correct the aggregate series of interest. Suppose that we are interested in recovering the share or persons of NRC and non-NRC types in specific labor force status, and call these $x_{N R C}$, and $x_{N N R C}$. Define our observed values from the classifier as $\hat{x}_{N R C}$, and $\hat{x}_{N N R C}$, and define the classification outcomes in terms of the following shares (with the convention $S_{\text {True|Classified }}$ ) as in Table $\mathrm{A} 3$.

Table A3: Classification Definitions

True \begin{tabular}{ccc}
\multicolumn{1}{c}{} & \multicolumn{2}{c}{ Classified } \\
\cline { 3 - 4 } NRC & $S_{N R C \mid N R C}$ & $S_{N R C \mid N N R C}$ \\
non-NRC & $S_{N N R C \mid N R C}$ & $S_{N N R C \mid N N R C}$
\end{tabular}

We can then write the observed values as a function of the true values and the share as follows

$$
\begin{gathered}
\hat{x}_{N R C}=S_{N R C \mid N R C} x_{N R C}+S_{N N R C \mid N R C} x_{N N R C} \\
\hat{x}_{N N R C}=S_{N R C \mid N N R C} x_{N R C}+S_{N N R C \mid N N R C} x_{N N R C}
\end{gathered}
$$

Thus if we know the shares in A3, we are left with a simple two-equation two-unknown linear system that will allow us to recover $x_{N R C}$ and $x_{N N R C}$. The first way to recover the shares in $\mathrm{A} 3$ is to use the classification errors from the training, reported in section A.1.2. The second approach is to use the restrictions implied by nature by some of the series. For example, the series or true values of employment share in R occupations for the NRC type during the training period, should be roughly zero. While the second approach is appealing, it can only be applied to the occupation series, and not to the NLF series, for which we apply the first approach. It is important to note that both approaches require the assumption that the classification errors are not correlated with the labor market status and occupation choice in the post-training period. 


\section{A.2. Model Derivations}

\section{A.2.1. Wage functions}

Taking the first order condition with respect to wages we have

$$
\tau\left(\frac{\partial J\left(x_{R, \varepsilon_{R}}, \Lambda\right)}{\partial x_{R, \varepsilon_{R}}}\right)\left[U^{\prime}\left(C_{e, R, \varepsilon}\right)\left(1-T_{e, R, \varepsilon}\right)-U^{\prime}\left(C_{u, R, \varepsilon}\right)\left(1-T_{u, R, \varepsilon}\right) b_{R, \varepsilon}\right]=(1-\tau)\left(\tilde{V}_{R, \varepsilon}(\Lambda)\right)\left(1-T_{\pi}\right)
$$

or

$$
\begin{aligned}
& \tilde{V}_{R, \varepsilon}(\Lambda)=\left[U^{\prime}\left(C_{e, R, \varepsilon}\right)\left(1-T_{e, R, \varepsilon}\right)-U^{\prime}\left(C_{u, R, \varepsilon}\right)\left(1-T_{u, R, \varepsilon}\right) b_{R, \varepsilon}\right] \frac{\tau}{1-\tau} \frac{1}{1-T_{\pi}} \frac{\partial J\left(x_{R, \varepsilon_{R}}, \Lambda\right)}{\partial x_{R, \varepsilon_{R}}} \\
& =\xi \frac{\tau}{1-\tau} \frac{1}{1-T_{\pi}} \frac{\partial J\left(x_{R, \varepsilon_{R}}, \Lambda\right)}{\partial x_{R, \varepsilon_{R}}}
\end{aligned}
$$

Where $\xi \equiv\left[U^{\prime}\left(C_{e, R, \varepsilon}\right)\left(1-T_{e, R, \varepsilon}\right)-U^{\prime}\left(C_{u, R, \varepsilon}\right)\left(1-T_{u, R, \varepsilon}\right) b_{R, \varepsilon}\right]$. Substituting for the marginal value of workers, and using the first order condition one period ahead, we can right the left hand side as

$$
\begin{aligned}
& \tilde{V}_{R, \varepsilon}(\Lambda)=U\left(\omega_{R, \varepsilon}\left(1-T_{e, R, \varepsilon}\right)\right)-U\left(b_{R, \varepsilon} \omega_{R, \varepsilon}\left(1-T_{u, R, \varepsilon}\right)\right)+\beta\left(1-\delta-\mu\left(\theta_{R, \varepsilon_{R}}\right)\right) \tilde{V}_{R, \varepsilon}\left(\Lambda^{\prime}\right)= \\
& =U\left(C_{e, R, \varepsilon}\right)-U\left(C_{u, R, \varepsilon}\right)+\beta\left(1-\delta-\mu\left(\theta_{R, \varepsilon_{R}}\right)\right) \xi \frac{\tau}{1-\tau} \frac{1}{1-T_{\pi}} \frac{\partial J\left(x_{R, \varepsilon_{R}}, \Lambda\right)}{\partial x_{R, \varepsilon_{R}}}
\end{aligned}
$$

Substitute for the marginal value of the firm we can write the right hand side as follows:

$$
\begin{aligned}
& \xi \frac{\tau}{1-\tau} \frac{1}{1-T_{\pi}} \frac{\partial J\left(x_{R, \varepsilon_{R}}, \Lambda\right)}{\partial x_{R, \varepsilon_{R}}}= \\
& \xi \frac{\tau}{1-\tau} \frac{1}{1-T_{\pi}}\left[\left(1-T_{\pi}\right)\left(f_{R} \varepsilon_{R} P_{R}-\omega_{R, \varepsilon_{R}}\right)+(1-\delta) \beta \frac{\partial J\left(x_{R, \varepsilon_{R}}^{\prime}, \Lambda^{\prime}\right)}{\partial x_{R, \varepsilon_{R}}^{\prime}}\right]
\end{aligned}
$$

Therefore we have 


$$
\begin{aligned}
& U\left(C_{e, R, \varepsilon}\right)-U\left(C_{u, R, \varepsilon}\right)+\beta\left(1-\delta-\mu\left(\theta_{R, \varepsilon_{R}}\right)\right) \xi \frac{\tau}{1-\tau} \frac{1}{1-T_{\pi}} \frac{\partial J\left(x_{R, \varepsilon_{R}}, \Lambda\right)}{\partial x_{R, \varepsilon_{R}}}= \\
& \xi \frac{\tau}{1-\tau} \frac{1}{1-T_{\pi}}\left[\left(1-T_{\pi}\right)\left(f_{R} \varepsilon_{R} P_{R}-\omega_{R, \varepsilon_{R}}\right)+(1-\delta) \beta \frac{\partial J\left(x_{R, \varepsilon_{R}}, \Lambda\right)}{\partial x_{R, \varepsilon_{R}}}\right] \\
& \Rightarrow \\
& U\left(C_{e, R, \varepsilon}\right)-U\left(C_{u, R, \varepsilon}\right)-\beta \mu\left(\theta_{R, \varepsilon_{R}}\right) \xi \frac{\tau}{1-\tau} \frac{1}{1-T_{\pi}} \frac{\partial J\left(x_{R, \varepsilon_{R}}, \Lambda\right)}{\partial x_{R, \varepsilon_{R}}}= \\
& \xi \frac{\tau}{1-\tau}\left(f_{R} \varepsilon_{R} P_{R}-\omega_{R, \varepsilon_{R}}\right) \\
& \Rightarrow \quad \frac{1-\tau}{\tau} \frac{1}{\xi}\left(U\left(C_{e, R, \varepsilon}\right)-U\left(C_{u, R, \varepsilon}\right)\right)-\beta \mu\left(\theta_{R, \varepsilon_{R}}\right) \frac{1}{1-T_{\pi}} \frac{\partial J\left(x_{R, \varepsilon_{R}}, \Lambda\right)}{\partial x_{R, \varepsilon_{R}}}= \\
& f_{R} \varepsilon_{R} P_{R}-\omega_{R, \varepsilon_{R}} \\
& \Rightarrow \quad \\
& \omega_{R, \varepsilon_{R}}=f_{R} \varepsilon_{R} P_{R}-\frac{1-\tau}{\tau} \frac{1}{\xi}\left(U\left(C_{e, R, \varepsilon}\right)-U\left(C_{u, R, \varepsilon}\right)\right)+\beta \theta_{R, \varepsilon_{R}} q\left(\theta_{R, \varepsilon_{R}}\right) \frac{1}{1-T_{\pi}} \frac{\partial J\left(x_{R, \varepsilon_{R}, \Lambda}\right)}{\partial x_{R, \varepsilon_{R}}}
\end{aligned}
$$

where we substitute the relationship $\mu\left(\theta_{R, \varepsilon_{R}}\right)=\theta_{R, \varepsilon_{R}} q\left(\theta_{R, \varepsilon_{R}}\right)$. Finally, we can use the steady state version of the first order condition for vacancies $\left(1-T_{\pi}\right) \kappa_{R, \varepsilon_{R}}=E\left[\beta q\left(\theta_{R, \varepsilon_{R}}\right) \frac{\partial J\left(x_{R, \varepsilon_{R}}^{\prime}, \Lambda^{\prime}\right)}{\partial x_{R, \varepsilon_{R}}^{\prime}}\right]$. This yields the general wage function

$$
\begin{aligned}
& \omega_{R, \varepsilon_{R}}=f_{R} \varepsilon_{R} P_{R}-\frac{1-\tau}{\tau} \frac{1}{\xi}\left(U\left(C_{e, R, \varepsilon}\right)-U\left(C_{u, R, \varepsilon}\right)\right)+\theta_{R, \varepsilon_{R}} \kappa_{R, \varepsilon_{R}}= \\
& f_{R} \varepsilon_{R} P_{R}-\frac{1-\tau}{\tau} \frac{U\left(C_{e, R, \varepsilon}\right)-U\left(C_{u, R, \varepsilon}\right)}{U^{\prime}\left(C_{e, R, \varepsilon}\right)\left(1-T_{e, R, \varepsilon}\right)-U^{\prime}\left(C_{u, R, \varepsilon}\right)\left(1-T_{u, R, \varepsilon}\right) b_{R, \varepsilon}}+\theta_{R, \varepsilon_{R}} \kappa_{R, \varepsilon_{R}}
\end{aligned}
$$

When we assume a CRRA utility function $U(C)=\frac{C^{1-\sigma}}{1-\sigma}$ and that there are no lump sum transfers to workers who are in the labor force then we can simplify further: 


$$
\begin{aligned}
& \frac{U\left(C_{e, R, \varepsilon}\right)-U\left(C_{u, R, \varepsilon}\right)}{U^{\prime}\left(C_{e, R, \varepsilon}\right)\left(1-T_{e, R, \varepsilon}\right)-U^{\prime}\left(C_{u, R, \varepsilon}\right)\left(1-T_{u, R, \varepsilon}\right) b_{R, \varepsilon}}= \\
& \frac{\frac{\left(C_{e, R, \varepsilon}\right)^{1-\sigma}}{1-\sigma}-\frac{\left(C_{u, R, \varepsilon}\right)^{1-\sigma}}{1-\sigma}}{\left(C_{e, R, \varepsilon}\right)^{-\sigma}\left(1-T_{e, R, \varepsilon}\right)-\left(C_{e, R, \varepsilon}\right)^{-\sigma}\left(1-T_{u, R, \varepsilon}\right) b_{R, \varepsilon}}= \\
& \frac{1}{1-\sigma} \frac{\left(\omega_{R, \varepsilon_{R}}\left(1-T_{e, R, \varepsilon}\right)\right)^{1-\sigma}-\left(b_{R, \varepsilon} \omega_{R, \varepsilon_{R}}\left(1-T_{u, R, \varepsilon}\right)\right)^{1-\sigma}}{\left(\omega_{R, \varepsilon_{R}}\left(1-T_{e, R, \varepsilon}\right)\right)^{-\sigma}\left(1-T_{e, R, \varepsilon}\right)-\left(b_{R, \varepsilon} \omega_{R, \varepsilon_{R}}\left(1-T_{u, R, \varepsilon}\right)\right)^{-\sigma}\left(1-T_{u, R, \varepsilon}\right) b_{R, \varepsilon}}= \\
& \frac{1}{1-\sigma} \frac{\left(\omega_{R, \varepsilon_{R}}\right)^{1-\sigma}\left(1-T_{e, R, \varepsilon}\right)^{1-\sigma}-\left(\omega_{R, \varepsilon_{R}}\right)^{1-\sigma}\left(1-T_{u, R, \varepsilon}\right)^{1-\sigma} b_{R, \varepsilon}^{1-\sigma}}{\left(\omega_{R, \varepsilon_{R}}\right)^{-\sigma}\left(1-T_{e, R, \varepsilon}\right)^{1-\sigma}-\left(\omega_{R, \varepsilon_{R}}\right)^{-\sigma}\left(1-T_{u, R, \varepsilon}\right)^{1-\sigma} b_{R, \varepsilon}^{1-\sigma}}= \\
& \frac{1}{1-\sigma} \frac{\left(\omega_{R, \varepsilon_{R}}\right)^{1-\sigma}\left[\left(1-T_{e, R, \varepsilon}\right)^{1-\sigma}-\left(1-T_{u, R, \varepsilon}\right)^{1-\sigma} b_{R, \varepsilon}^{1-\sigma}\right]}{\left(\omega_{R, \varepsilon_{R}}\right)^{-\sigma}\left[\left(1-T_{e, R, \varepsilon}\right)^{1-\sigma}-\left(1-T_{u, R, \varepsilon}\right)^{1-\sigma} b_{R, \varepsilon}^{1-\sigma}\right]}= \\
& \frac{1}{1-\sigma} \omega_{R, \varepsilon_{R}}
\end{aligned}
$$

and as a result the wage function simplifies to

$$
\begin{aligned}
& \omega_{R, \varepsilon_{R}}=f_{R} \varepsilon_{R} P_{R}+\theta_{R, \varepsilon_{R}} \kappa_{R, \varepsilon_{R}}-\frac{1-\tau}{\tau} \frac{1}{1-\sigma} \omega_{R, \varepsilon_{R}} \\
& \Rightarrow \\
& \omega_{R, \varepsilon_{R}}=\frac{1}{1+\frac{1-\tau}{\tau} \frac{1}{1-\sigma}}\left[f_{R} \varepsilon_{R} P_{R}+\theta_{R, \varepsilon_{R}} \kappa_{R, \varepsilon_{R}}\right]
\end{aligned}
$$

Armed with this wage function we move to the optimality condition for vacancies

$$
\frac{\kappa_{R, \varepsilon_{R}}}{q\left(\theta_{R, \varepsilon_{R}}\right)}=\beta\left[f_{R} \varepsilon_{R} P_{R}-\omega_{R, \varepsilon_{R}}+(1-\delta) \frac{\kappa_{R, \varepsilon_{R}}}{q\left(\theta_{R, \varepsilon_{R}}\right)}\right]
$$

Substituting the wage function we have

$$
\frac{\kappa_{R, \varepsilon_{R}}}{q\left(\theta_{R, \varepsilon_{R}}\right)}=\beta\left[f_{R} \varepsilon_{R} P_{R}-\frac{1}{1+\frac{1-\tau}{\tau} \frac{1}{1-\sigma}}\left[f_{R} \varepsilon_{R} P_{R}+\theta_{R, \varepsilon_{R}} \kappa_{R, \varepsilon_{R}}\right]+(1-\delta) \frac{\kappa_{R, \varepsilon_{R}}}{q\left(\theta_{R, \varepsilon_{R}}\right)}\right]
$$

and once we add the assumption that hiring cost if proportional to productivity we get 


$$
\begin{aligned}
& \frac{\kappa_{0}}{q\left(\theta_{R, \varepsilon_{R}}\right)}=\beta\left[1-\frac{1}{1+\frac{1-\tau}{\tau} \frac{1}{1-\sigma}}\left[1+\theta_{R, \varepsilon_{R}} \kappa_{0}\right]+(1-\delta) \frac{\kappa_{0}}{q\left(\theta_{R, \varepsilon_{R}}\right)}\right] \\
& \frac{\kappa_{0}}{q\left(\theta_{R, \varepsilon_{R}}\right)}(1-\beta(1-\delta))=\beta \frac{\frac{1-\tau}{\tau} \frac{1}{1-\sigma}-\theta_{R, \varepsilon_{R}} \kappa_{0}}{1+\frac{1-\tau}{\tau} \frac{1}{1-\sigma}} \\
& \kappa_{0}\left[\frac{1-\beta(1-\delta)}{q\left(\theta_{R, \varepsilon_{R}}\right)}+\beta \frac{\theta_{R, \varepsilon_{R}}}{1+\frac{1-\tau}{\tau} \frac{1}{1-\sigma}}\right]=\beta \frac{\frac{1-\tau}{\tau} \frac{1}{1-\sigma}}{1+\frac{1-\tau}{\tau} \frac{1}{1-\sigma}} \\
& \kappa_{0}=\frac{\frac{\frac{1-\tau}{\tau} \frac{1}{1-\sigma}}{1+\frac{1-\tau}{\tau} \frac{1}{1-\sigma}}}{\frac{1-\beta(1-\delta)}{q\left(\theta_{R, \varepsilon_{R}}\right)}+\beta \frac{\theta_{R, \varepsilon_{R}}}{1+\frac{1-\tau}{\tau} \frac{1}{1-\sigma}}}
\end{aligned}
$$




\section{A.3. Productivity cutoffs}

Denote the value of staying out of the labor force by $V_{o, \varepsilon}$, a constant number in steady state.

The value of employment in occupation $\mathrm{R}$ with idiosyncratic productivity $\varepsilon_{R}$ is

$$
\begin{aligned}
V_{e, R, \varepsilon} & =\frac{\left(\omega_{R, \varepsilon_{R}}\left(1-T_{e, R, \varepsilon_{R}}\right)\right)^{1-\sigma}}{1-\sigma}+\beta(1-\delta) V_{e, R, \varepsilon}+\beta \delta V_{u, R, \varepsilon} \\
V_{e, R, \varepsilon} & =\frac{1}{1-\beta(1-\delta)}\left[\frac{\left.\left(\frac{f_{R} \varepsilon_{R} P_{R}}{1+\frac{1-\tau}{\tau} \frac{1}{1-\sigma}}\left[1+\theta_{R, \varepsilon_{R}} \kappa_{0}\right]\left(1-T_{e, R, \varepsilon_{R}}\right)\right)^{1-\sigma}\right]}{1-\sigma}\right]+\frac{\beta \delta}{1-\beta(1-\delta)} V_{u, R, \varepsilon}
\end{aligned}
$$

where we substituted the explicit wage function under the assumption of proportional hiring costs.

The value of unemployment in occupation $\mathrm{R}$ with idiosyncratic productivity $\varepsilon_{R}$ is

$$
\begin{aligned}
& V_{u, R, \varepsilon}=\frac{\left(b_{R, \varepsilon_{R}} \omega_{R, \varepsilon_{R}}\left(1-T_{u, R, \varepsilon_{R}}\right)\right)^{1-\sigma}}{1-\sigma}+\beta\left(1-\mu\left(\theta_{R, \varepsilon_{R}}\right)\right) V_{u, R, \varepsilon}+\beta \mu\left(\theta_{R, \varepsilon_{R}}\right) V_{e, R, \varepsilon} \\
& V_{u, R, \varepsilon}(1-\beta)=\left[\frac{\left.\left(b_{R, \varepsilon_{R}} \frac{f_{R} \varepsilon_{R} P_{R}}{1+\frac{1-\tau}{\tau} \frac{1}{1-\sigma}}\left[1+\theta_{R, \varepsilon_{R}} \kappa_{0}\right]\left(1-T_{u, R, \varepsilon_{R}}\right)\right)^{1-\sigma}\right]}{1-\sigma}\right]+\beta \mu\left(\theta_{R, \varepsilon_{R}}\right)\left[V_{e, R, \varepsilon}-V_{u, R, \varepsilon}\right]
\end{aligned}
$$

Note that the first order condition of the bargaining problem implies that

$$
V_{e, R, \varepsilon}-V_{u, R, \varepsilon}=\xi \frac{\tau}{1-\tau} \frac{1}{1-T_{\pi}} \frac{\partial J\left(x_{R, \varepsilon_{R}}, \Lambda\right)}{\partial x_{R, \varepsilon_{R}}}
$$

and the first order condition with respect to vacancies implies that

$$
\frac{\partial J\left(x_{R, \varepsilon_{R}}, \Lambda\right)}{\partial x_{R, \varepsilon_{R}}}=\frac{\left(1-T_{\pi}\right) \kappa_{0} P_{R} f_{R} \varepsilon_{R}}{\beta q\left(\theta_{R, \varepsilon_{R}}\right)}
$$

Substituting, we have

$$
\begin{aligned}
& V_{u, R, \varepsilon}(1-\beta)=\left[\frac{\left(b_{R, \varepsilon_{R}} \frac{f_{R} \varepsilon_{R} P_{R}}{1+\frac{1-\tau}{\tau} \frac{1}{1-\sigma}}\left[1+\theta_{R, \varepsilon_{R}} \kappa_{0}\right]\left(1-T_{u, R, \varepsilon_{R}}\right)\right)^{1-\sigma}}{1-\sigma}\right] \\
& +\theta_{R, \varepsilon_{R}} \xi \frac{\tau}{1-\tau} \kappa_{0} P_{R} f_{R} \varepsilon_{R}
\end{aligned}
$$


Now we can substitute for $\xi$, taking into account the CRRA assumption

$$
\begin{aligned}
& \xi=U^{\prime}\left(C_{e, R, \varepsilon}\right)\left(1-T_{e, R, \varepsilon}\right)-U^{\prime}\left(C_{u, R, \varepsilon}\right)\left(1-T_{u, R, \varepsilon}\right) b_{R, \varepsilon} \\
& =\left(\omega_{R, \varepsilon_{R}}\right)^{-\sigma}\left[\left(1-T_{e, R, \varepsilon}\right)^{1-\sigma}-\left(1-T_{u, R, \varepsilon}\right)^{1-\sigma} b_{R, \varepsilon}^{1-\sigma}\right] \\
& =\left(\frac{f_{R} \varepsilon_{R} P_{R}}{1+\frac{1-\tau}{\tau} \frac{1}{1-\sigma}}\left[1+\theta_{R, \varepsilon_{R}} \kappa_{0}\right]\right)^{-\sigma}\left[\left(1-T_{e, R, \varepsilon}\right)^{1-\sigma}-\left(1-T_{u, R, \varepsilon}\right)^{1-\sigma} b_{R, \varepsilon}^{1-\sigma}\right]
\end{aligned}
$$

Therefore

$$
\begin{aligned}
& V_{u, R, \varepsilon}(1-\beta)=\left[\frac{\left(b_{R, \varepsilon_{R}} \frac{f_{R} \varepsilon_{R} P_{R}}{1+\frac{1-\tau}{\tau} \frac{1}{1-\sigma}}\left[1+\theta_{R, \varepsilon_{R}} \kappa_{0}\right]\left(1-T_{u, R, \varepsilon_{R}}\right)\right)^{1-\sigma}}{1-\sigma}\right] \\
& +\left(\frac{f_{R} \varepsilon_{R} P_{R}}{1+\frac{1-\tau}{\tau} \frac{1}{1-\sigma}}\left[1+\theta_{R, \varepsilon_{R}} \kappa_{0}\right]\right)^{-\sigma}\left[\left(1-T_{e, R, \varepsilon}\right)^{1-\sigma}-\left(1-T_{u, R, \varepsilon}\right)^{1-\sigma} b_{R, \varepsilon}^{1-\sigma}\right] \theta_{R, \varepsilon_{R}} \frac{\tau}{1-\tau} \kappa_{0} P_{R} f_{R} \varepsilon_{R}
\end{aligned}
$$

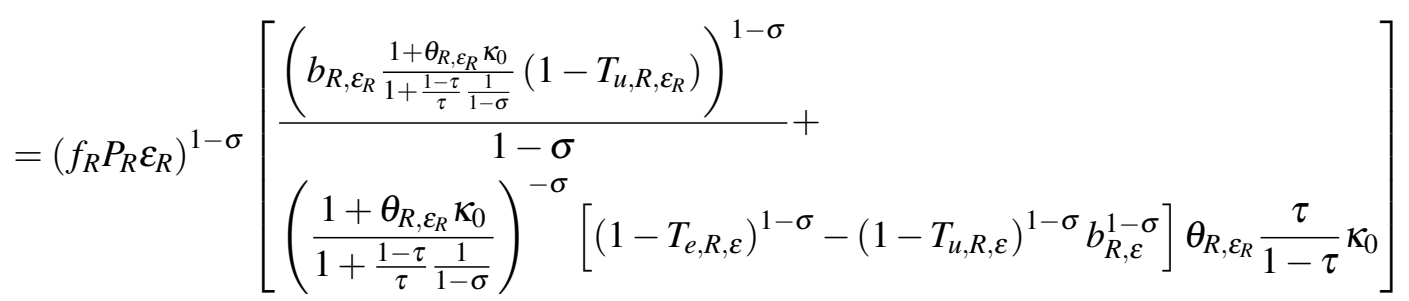

or

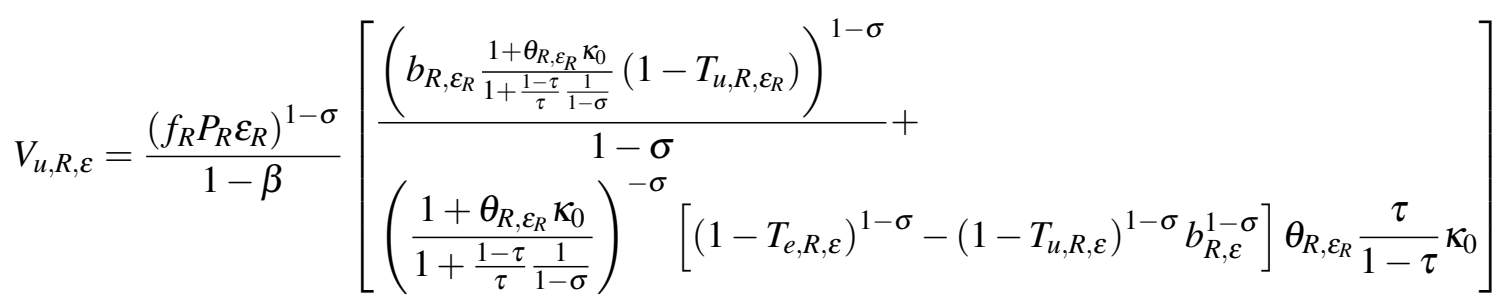

Note that the term in brackets is constant in steady state because it is a combination of exogenous parameters and the tightness ratio, which we have shown to be independent of the productivity parameters. Defining the term in brackets by $\urcorner_{R}$ and the analogue for NRM by $\urcorner_{N R M}$ we can express the values of unemployment in both occupations as 


$$
\begin{aligned}
V_{u, R, \varepsilon} & \left.=\frac{\left(f_{R} P_{R} \varepsilon_{R}\right)^{1-\sigma}}{1-\beta}\right\rceil_{R} \\
V_{u, R, \varepsilon} & \left.=\frac{\left(f_{N R M} P_{N R M} \varepsilon_{N R M}\right)^{1-\sigma}}{1-\beta}\right\rceil_{N R M}
\end{aligned}
$$




\section{A.4. Derivation of Change in Welfare by Group}

The welfare change due to automation for those who switched form R to NRM is given by

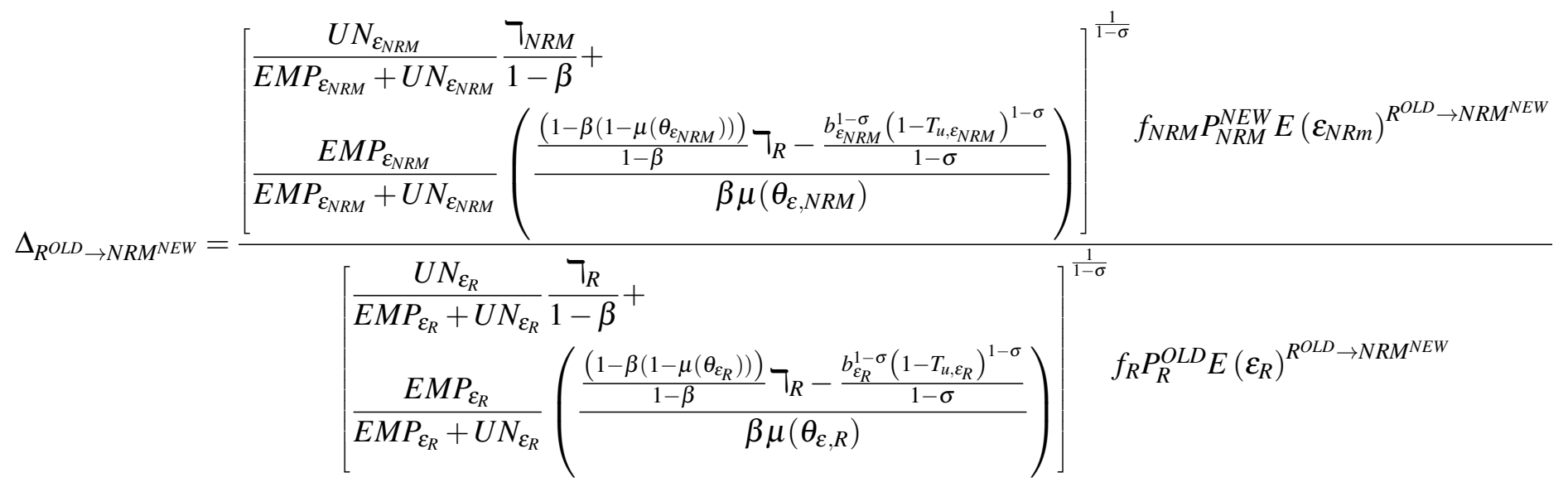

which given our calibration targets can be simplified to

$$
\Delta_{R} O L D \rightarrow N R M^{N E W}=\frac{f_{N R M} P_{N R M}^{N E W} E\left(\varepsilon_{N R m}\right)^{R^{O L D} \rightarrow N R M^{N E W}}}{f_{R} P_{R}^{O L D} E\left(\varepsilon_{R}\right)^{R^{O L D} \rightarrow N R M^{N E W}}}
$$

where we note that in the numerator we draw the $\varepsilon_{N R M}$ abilities for these individuals that transitions to NRM.

The average change in welfare for $\mathrm{R}$ workers who leave the labor force is given by

$$
\Delta_{R} O L D \rightarrow N L F \text { NEW }=\frac{\frac{1}{1-\beta} \frac{1}{1-\sigma}\left(b_{O}\right)^{\frac{1}{1-\sigma}}}{\left[\begin{array}{l}
\frac{U N_{\varepsilon_{R}}}{E M P_{\varepsilon_{R}}+U N_{\varepsilon_{R}}} \frac{\urcorner_{R}}{1-\beta}+ \\
\left.\frac{E M P_{\varepsilon_{R}}}{E M P_{\varepsilon_{R}}+U N_{\varepsilon_{R}}}\left(\frac{\left.\left.\frac{\left(1-\beta\left(1-\mu\left(\theta_{\varepsilon_{R}}\right)\right)\right.}{1-\beta}\right\urcorner_{R}-\frac{b_{\varepsilon_{R}}^{1-\sigma}\left(1-T_{u, \varepsilon_{R}}\right)^{1-\sigma}}{1-\sigma}\right)}{\beta \mu\left(\theta_{\varepsilon, R}\right)}\right)\right]^{\frac{1}{1-\sigma}} f_{R} P_{R}^{O L D} E\left(\varepsilon_{R}\right)^{R^{O L D} \rightarrow N L F^{N E W}}
\end{array}\right.}
$$

Note that by definition, there is an individual who is indifferent between participating in the labor force and not. Then, since the value of being outside of the labor force does not change in this analysis, we can rewrite the above expression as

$$
\Delta_{R^{O L D} \rightarrow N L F^{N E W}}=\frac{\varepsilon_{R}^{*, O L D}}{E\left(\varepsilon_{R}\right)^{R^{O L D} \rightarrow N L F^{N E W}}}
$$

The average change in the consumption equivalence for those who worked in Non-Routine Manual occupations, and continued working in Non-Routine Manual occupations is given by

$$
\Delta_{N R M^{O L D} \rightarrow N R M^{N E W}}=\frac{P_{N R M}^{N E W}}{P_{N R M}^{O L D}}
$$


The average change in consumption equivalent welfare for those who were outside the labor force and started working in Non-Routine-Manual occupations post-automation is given by

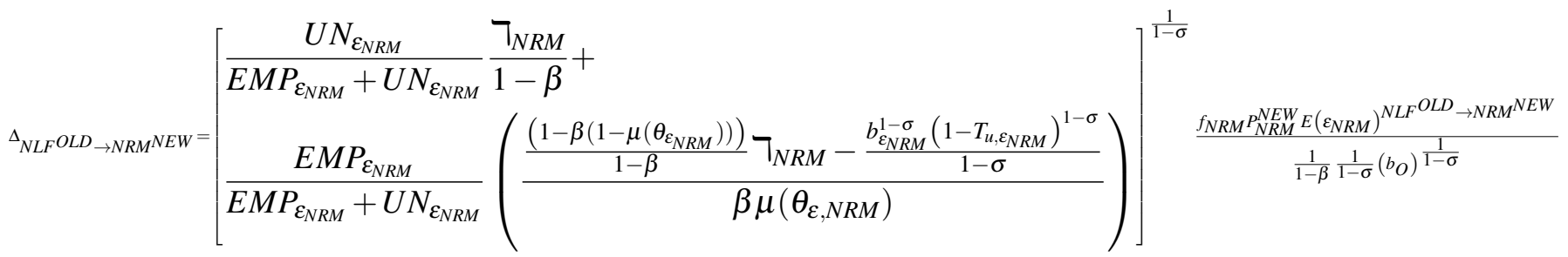

As above, given the cutoff value of those individuals who are outside the labor force we can rewrite this expression as

$$
\Delta_{N L F} O L D \rightarrow N R M^{N E W}=\frac{P_{N R M}^{N E W} E\left(\varepsilon_{N R M}\right)^{N L F^{O L D} \rightarrow N R M^{N E W}}}{P_{N R M}^{O L D} \varepsilon_{N R M}^{*, O L D}}
$$




\section{A.5. Alternative calibration of $\rho$}

Table A4: Alternative calibration with $\rho=0.5$

\begin{tabular}{|c|c|c|c|c|c|c|}
\hline & $\begin{array}{c}\text { ICT } \\
\text { Change }\end{array}$ & Retraining & UI & UBI & $\begin{array}{c}\text { NLF } \\
\text { Benefits }\end{array}$ & Taxation \\
\hline \multicolumn{7}{|l|}{ Labor states } \\
\hline$\Phi$ NLF & 2.091 & -2.149 & -2.133 & 5.751 & 14.743 & -5.013 \\
\hline$\Phi \mathrm{R}$ & -3.896 & 0.526 & 1.584 & -4.673 & -11.279 & 3.709 \\
\hline$\Phi$ NRM & 1.805 & 1.623 & 0.550 & -1.078 & -3.464 & 1.304 \\
\hline Emp. Rate R & 0.950 & 0.95 & 0.945 & 0.945 & 0.950 & 0.950 \\
\hline Emp. Rate NRM & 0.950 & 0.95 & 0.944 & 0.944 & 0.950 & 0.950 \\
\hline$\Delta Y_{N R C}$ & 1.200 & 0.379 & 0.119 & -14.439 & -7.858 & -2.163 \\
\hline$\Delta Y_{R}$ & -4.155 & 1.316 & 0.302 & -4.648 & -11.965 & 2.973 \\
\hline$\Delta Y_{N R M}$ & 9.664 & 4.144 & -0.438 & -3.548 & -12.495 & 3.784 \\
\hline$\Delta \mathbf{G D P}$ & 12.140 & 1.327 & 0.282 & -9.920 & -9.748 & 0.195 \\
\hline$\Phi$ NRC labor tax & 0.00 & -1.524 & -0.449 & 35.500 & 24.587 & 10.355 \\
\hline \multicolumn{7}{|l|}{ Wages } \\
\hline$\Delta \omega_{R}$ & -6.154 & -0.093 & 0.516 & -7.142 & 3.240 & -4.112 \\
\hline$\Delta \omega_{N R M}$ & 2.149 & -3.129 & 0.730 & -6.139 & 2.747 & -3.590 \\
\hline$\Delta \omega_{N R C}$ & 23.373 & 0.901 & 0.001 & 8.108 & -3.587 & 4.451 \\
\hline$\Delta \omega_{N R C}:$ after tax & 23.373 & 0.766 & 0.157 & -11.240 & -9.151 & -2.606 \\
\hline \multicolumn{7}{|c|}{ Welfare: Consumption Equivalence } \\
\hline$\Delta: R^{\text {Old }} \rightarrow \Delta R^{\text {New }}$ & -6.60 & 0.80 & 1.96 & 6.18 & 3.29 & 10.20 \\
\hline$\Delta: R^{\text {Old }} \rightarrow \Delta N R M^{N e w}$ & -1.70 & NA & 2.34 & 9.09 & NA & 10.50 \\
\hline$\Delta: R^{\text {Old }} \rightarrow \Delta N L F^{N e w}$ & -3.60 & 0.20 & NA & 26.50 & 16.50 & NA \\
\hline$\Delta: N R M^{\text {Old }} \rightarrow \Delta R^{\text {New }}$ & NA & -1.00 & NA & NA & 3.04 & NA \\
\hline$\Delta: N R M^{\text {Old }} \rightarrow \Delta N R M^{N e w}$ & 2.50 & -2.50 & 2.15 & 6.77 & 2.78 & 10.80 \\
\hline$\Delta: N R M^{\text {Old }} \rightarrow \Delta N L F^{\text {New }}$ & NA & -1.60 & NA & 27.08 & 16.27 & NA \\
\hline$\Delta: N L F^{\text {Old }} \rightarrow \Delta R^{\text {New }}$ & NA & NA & 2.28 & NA & NA & 5.83 \\
\hline$\Delta: N L F^{\text {Old }} \rightarrow \Delta N R M^{\text {New }}$ & 1.90 & 10.44 & 2.39 & NA & NA & 6.10 \\
\hline$\Delta: N L F^{\text {Old }} \rightarrow \Delta N L F^{N e w}$ & 0.00 & 0.00 & 0.00 & 34.60 & 34.66 & 0.00 \\
\hline$\Delta: N R C^{\text {Old }} \rightarrow \Delta N R C^{N e w}$ & 22.30 & 2.05 & 0.72 & -21.70 & -22.50 & -5.30 \\
\hline
\end{tabular}

Notes: (i) $\Phi$ denotes percentage point change; (ii) $\Delta$ denotes percentage change; (iii) the reference point for the first column is the steady state beofre the ICT price decline; (iv) the reference point for columns 2-6 is the steady state after the ICT price decline. 
Table A5: Alternative calibration with $\rho=-0.5$

\begin{tabular}{|c|c|c|c|c|c|c|}
\hline & $\begin{array}{c}\text { ICT } \\
\text { Change }\end{array}$ & Retraining & $\overline{\mathrm{UI}}$ & $\overline{\mathrm{UBI}}$ & $\begin{array}{c}\text { NLF } \\
\text { Benefits }\end{array}$ & Taxation \\
\hline \multicolumn{7}{|l|}{ Labor states } \\
\hline$\Phi \mathrm{NLF}$ & 2.258 & -2.186 & -2.356 & 6.202 & 15.624 & -5.626 \\
\hline$\Phi \mathrm{R}$ & -3.742 & 0.373 & 1.628 & -4.897 & -11.877 & 4.089 \\
\hline$\Phi$ NRM & 1.484 & 1.733 & 0.723 & -1.308 & -3.837 & 1.533 \\
\hline Emp. Rate R & 0.950 & 0.95 & 0.946 & 0.946 & 0.950 & 0.950 \\
\hline Emp. Rate NRM & 0.950 & 0.95 & 0.946 & 0.946 & 0.950 & 0.950 \\
\hline$\Delta Y_{N R C}$ & 1.232 & 0.237 & 0.179 & -13.886 & -8.249 & -1.882 \\
\hline$\Delta Y_{R}$ & -3.335 & 0.053 & -0.291 & -5.671 & -13.349 & 2.942 \\
\hline$\Delta Y_{N R M}$ & 5.458 & 6.160 & -0.666 & -4.868 & -14.480 & 4.457 \\
\hline$\Delta$ GDP & 11.894 & 0.733 & -0.256 & -10.422 & -10.900 & -0.095 \\
\hline$\Phi$ NRC labor tax & 0.00 & -1.281 & -0.650 & 35.290 & 25.816 & 9.664 \\
\hline \multicolumn{7}{|l|}{ Wages } \\
\hline$\Delta \omega_{R}$ & -7.231 & 0.091 & -0.303 & -7.447 & 2.917 & -4.788 \\
\hline$\Delta \omega_{N R M}$ & 6.434 & -5.453 & 0.443 & -5.604 & 3.529 & -4.406 \\
\hline$\Delta \omega_{N R C}$ & 23.224 & 0.696 & -0.435 & 6.972 & -4.443 & 4.241 \\
\hline$\Delta \omega_{N R C}:$ after tax & 23.224 & 0.796 & 0.145 & -14.375 & -12.314 & -3.051 \\
\hline \multicolumn{7}{|c|}{ Welfare: Consumption Equivalence } \\
\hline$\Delta: R^{\text {Old }} \rightarrow \Delta R^{\text {New }}$ & -7.00 & 1.42 & 1.78 & 6.24 & 3.65 & 10.00 \\
\hline$\Delta: R^{\text {Old }} \rightarrow \Delta N R M^{N e w}$ & -0.40 & NA & 3.00 & 15.04 & 3.87 & 10.21 \\
\hline$\Delta: R^{\text {Old }} \rightarrow \Delta N L F^{N e w}$ & -4.30 & NA & NA & 25.70 & 16.30 & NA \\
\hline$\Delta: N R M^{\text {Old }} \rightarrow \Delta R^{\text {New }}$ & NA & -1.62 & NA & NA & NA & NA \\
\hline$\Delta: N R M^{\text {Old }} \rightarrow \Delta N R M^{N e w}$ & 6.64 & -4.35 & 2.50 & 7.99 & 4.10 & 10.43 \\
\hline$\Delta: N R M^{\text {Old }} \rightarrow \Delta N L F^{\text {New }}$ & NA & -2.55 & NA & 26.82 & 16.90 & NA \\
\hline$\Delta: N L F^{\text {Old }} \rightarrow \Delta R^{N e w}$ & NA & 0.90 & 2.16 & NA & NA & 5.71 \\
\hline$\Delta: N L F^{\text {Old }} \rightarrow \Delta N R M^{\text {New }}$ & 4.00 & 9.96 & 2.51 & NA & NA & 5.98 \\
\hline$\Delta: N L F^{\text {Old }} \rightarrow \Delta N L F^{\text {New }}$ & 0.00 & 0.00 & 0.00 & 33.60 & 33.60 & 0.00 \\
\hline$\Delta: N R C^{\text {Old }} \rightarrow \Delta N R C^{N e w}$ & 22.46 & 1.81 & 0.00 & -22.50 & -24.00 & -5.30 \\
\hline
\end{tabular}

Notes: (i) $\Phi$ denotes percentage point change; (ii) $\Delta$ denotes percentage change; (iii) the reference point for the first column are relative to the steady state before the ICT price decline; (iv) the reference point for columns 2-6 is the steady state after the ICT price decline. 


\section{A.6. Elasticity of unemployment duration to unemployment benefits}

In the context of the UI and UBI experiment, a key channel through which these policies operate is via the bargaining problem and its impact on the wage and vacancies posting by firms. To discipline our analysis we required the model to match the elasticity of unemployment duration to unemployment benefits; different values of this elasticity have vastly different implications for the impact of different policy reforms. As such we require our model to match an elasticity value of 1 , which is within the range of the empirical counterpart (see for example Meyer (1990) and Chetty (2008)).

To match this elasticity in the model we solve for the labor market equilibrium for different individuals and for different values of unemployment transfers. We then estimate the aggregate resulting tightness ratio and job finding rates, from which we calculate the elasticity of unemployment duration to unemployment transfers. We follow the approach in Yedid-Levi (2016) that allows us to match the elasticity of unemployment duration to unemployment benefits, while maintaining log preferences. In this modification we introduce an additional parameter that links the bargaining power of the worker with labor market tightness, in a way that tames the response of wages to changes in UI benefits. Formally, the bargaining power $\tau$ is now expressed as $\tau(\theta)=\frac{\tau_{0}}{\tau_{0}+\left(1-\tau_{0}\right)\left(\frac{\theta^{s s}}{\theta}\right)^{\zeta}}{ }^{30}$

Importantly, this implies that this alternative parametrization of the model does not affect any of the results presented until Section 6 since the value of $\tau$ is not changed as long as the tightness ratio does not deviate from its steady state value. Indeed in Section 5 following the ICT price change the tightness ratio is not altered.

To identify $\zeta$ we repeat the discussed above analysis and reestimate the elasticity of unemployment duration to unemployment benefits until the model matches the micro elasticity, converging on a value of $\zeta=20$.

Thus to summarize, until section 6 , given that the unemployment rate is constant, the elasticity of unemployment duration to unemployment benefits is quantitatively an irrelevant moment. In Section 6 where unemployment reacts to the changes in UI and UBI, we verify that the model matches the observed micro elasticity of unemployment duration to unemployment benefits.

\footnotetext{
${ }^{30}$ Note that when $\zeta=0$ then the model converges to the benchmark case with constant bargaining power.
} 